\title{
FEASIBILITY OF LOW-CARBON PERMEABLE PAVEMENT SYSTEMS (PPS) FOR STORMWATER MANAGEMENT
}

\author{
Kiran Tota-Maharaj ${ }^{1 *}$, Blessing Oluwaseun Adeleke ${ }^{2}$, Chad Staddon $^{3}$ and Faisal Sweileh ${ }^{4}$ \\ ${ }^{1}$ Aston Infrastructure \& Sustainable Engineering School, College of Engineering and Physical Science, Department of Civil \\ Engineering, Aston University, Birmingham, B4 7ET, UK \\ ${ }^{2}$ School of Engineering, Faculty of Computing, Engineering and Science, University of South Wales, Pontypridd, CF37 1DL, \\ UK \\ ${ }^{3,4}$ Faculty of Environment and Technology, Civil and Environmental Engineering Cluster, University of the West of England \\ Bristol, BS16 1QY, UK
}

Received 1 July 2020; received in revised form 10 December 2020; accepted 10 April 2021

\begin{abstract}
The sharp increase in the utilisation and demand of construction materials across the world, especially in road, pavements and transportation sectors has resulted in an unsustainable surge in the amount of carbon emissions. This study investigated the use of low-carbon materials in permeable pavements systems (PPS) and the effects of various low-carbon engineered materials on the mechanical, absorption and infiltration performance of PPS according to relevant standards. This was achieved by the critical analysis of four (4) different materials (recycled grit, recycled glass, recycled rubber) and comparing their performance with normal materials used in conventional pavements. The four materials were implemented into concrete mixes of the permeable pavers and embedded in various layers and sub-sections making up the permeable pavement structure. As a result, the outcome required of this research is to find which mix of concrete blocks (permeable pavers) perform the best when tested for absorption and compression and which permeable pavement works best when tested for infiltration. Compression test was utilised to establish the maximum allowable compressive force, while the absorption test identified the concrete mix that could hold the least amount of water when soaked in water for 24 hours. This was expected to reduce the possibility of breakage of the concrete blocks. Finally, the infiltration test was employed to establish the best performing pavement material based on the rate and amount of infiltration of a fixed volume of effluent. The results obtained from the laboratory tests shows improved performances of the pavements embedded with recycled materials. Therefore, it can be recommended that the use of recycled materials in the development of low-carbon permeable pavements, possesses the ability to perform efficiently in comparison with conventional PPS in the construction and built environment sectors.
\end{abstract}

Keywords: Sustainable Drainage Systems (SuDS), Recycled Construction Materials, Permeable Pavements, Carbon Footprint, Stormwater

(C) 2020 Journal of Urban and Environmental Engineering (JUEE). All rights reserved.

*Correspondence to: Tota-Maharaj, Tel: +44 1212 044296, E-mail: k.tota-maharaj@aston.ac.uk 


\section{INTRODUCTION}

The rapid increase in the use and demand of construction materials across the world in recent years, with a focus on the transportation sectors for constructing and maintaining pavements have resulted in high amounts of emissions of carbon dioxide $\left(\mathrm{CO}_{2}\right)$. However, the use of recycled materials in various civil engineering applications promotes an increase in sustainability, and consequently lowers the carbon content and emissions from using the usual constructional materials.

These dangerous emissions have exacerbated some problems the world is facing with respect to global warming, and the capabilities of dealing with fluctuating weather patterns that results to excessive precipitations (leading to stormwater flooding, causing major infrastructural damage) and dry antecedent periods with no or very little rainfall. Sustainable drainage systems (SuDS) such as permeable pavement systems (PPS) are an effective solution for sustainable stormwater management with the ease of construction, implementation and maintenance. However, the use of low carbon materials for constructing permeable pavements, is a sustainable approach for addressing the excesses precipitation currently facing the world. This study was carried out to give more insight into the applications of low carbon materials for pavement engineering, investigate the structural performance/integrity, and hydrological performance of low carbon permeable pavements block systems.

\section{Sustainable drainage systems (SuDS) \& permeable pavements}

Permeable Pavement is a type of pavement composed of concrete with a permeable surface, which often includes asphalt with an underlying stone reservoir or open pore pavers (Fig. 1). Moreover, it is often called a green pavement that prevents water from collecting on it, rather it allows water to flow through it without causing any structural damage to the constituent materials. Figure 1 illustrates a permeable pavement cross section that shows the combination of layers composing of a permeable sub-base, a permeable base, a permeable bedding layer (where applicable), and a permeable surface. Furthermore, these layers are designed to withstand traffic loading while distributing stresses and also to enable water percolation.

\section{Benefits of Permeable Pavements Systems}

These pavements are often used for their benefits. Firstly, permeable pavement does not produce a significant 'heat island', which is an area on the pavement where it is much warmer than its surroundings. Also, these types of pavement can be made using recycled materials, as this puts less pressure on the environment for the need of producing materials to build driveways. In addition, the formation of ice on the surface of these pavements is considerably low in freezing temperatures. This is because water and precipitation can seep into the pavement, this makes it safer for driving and walking across the driveway as it will remain warm (Greenblue-Urban, 2017).

\section{Applications of PPS as a Sustainable drainage system (SuDS)}

Permeable pavements are usually used for driveways, walkways, patios, sidewalks, courtyards, alleys, parking lots, and in low-traffic roadways, generally with speed limits of $55 \mathrm{kph}(35 \mathrm{mph})$ or lower. PPS can also be used in recreational and park-related applications such as playground spray pools, areas around water fountains, or as permeable buffers around tree beds and planters. Since permeable pavements is beneficial for pedestrian and vehicular applications, they are profoundly suitable for use in urban areas where the dual purpose for stormwater management and a usable surface are required. Furthermore, permeable pavements can be utilized in retrofit applications to give stormwater management in space restricted locations. PPS can also be deliberately set to acknowledge clean sudden spike in demand for neighbouring useage, for example, walkways or rooftops. Moreover, Permeable pavements can hold toxins and improve the nature of stormwater. A few investigations have assessed the chance of utilizing this water for non-consumable uses in structures, for example, toilet flushing, garden watering, and vehicle washing, among others. Pratt (1999) played out a contextual investigation at a UKbased inn whose building had $400 \mathrm{~m}^{2}$ of rooftop zone and $325 \mathrm{~m}^{2}$ of parking zone. Stormwater precipitated on the two surfaces would be put away in the parking subbase. The parking surface contained permeable blocks that permitted infiltration of stormwater into the subbase, while the water put away in the sub-base was associated with a tank in the lodging and utilized for toilet flushing. However, the water stockpiling limit on the pavement was around equivalent to $34 \mathrm{~m}^{3}$. 


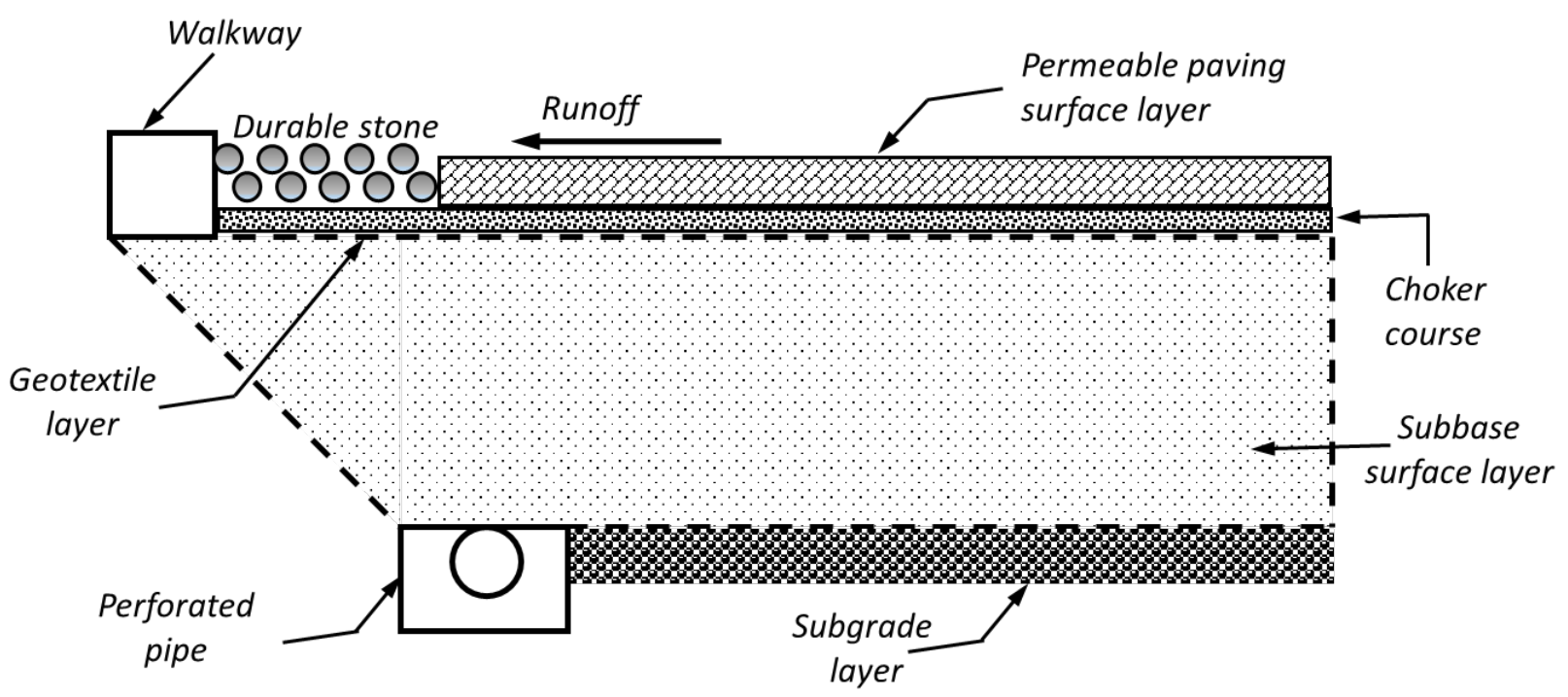

Fig. 1 Permeable Pavement cross section

Hammes et al. (2018) also assessed the presentation of two permeable pavements regarding the amount and nature of infiltrated stormwater, focusing on its utilization in exercises that permit the utilization of nonconsumable water. Figure 2 illustrates the pavements structures for models A and B. The investigated porous asphalt materials possessed a mean of 70 and $80 \%$ infiltration respectively. The lower infiltration value for model A was principally due to the availability of the filter course. A positive influence of the pavements was seen in certain parameters of water quality. Be that as it may, the requirement for an extra treatment of the water to adjust it to the normal quality for use was verified. Also, it was proposed to utilize the permeable pavement in a parking area of the Federal University of Santa Catarina (Brazil) for stormwater infiltration, storage and consequent use in toilets and urinals flushing. The potential for consumable water savings would be about $53 \%$.

\section{Hydrological performance}

Palla et al. (2015) directed a laboratory study at exploring the hydrological reaction of a permeable pavement when subjected to different amounts of precipitation and slopes. The investigation analysed two sorts of pervious pavements: a $210 \mathrm{~mm}$ deep concrete cell (CC) and a $190 \mathrm{~mm}$ deep pervious block (PB), with two filter layers made of reused glass aggregate and a blend of rock and coarse sand. The hydrological reaction was examined by calculating the discharge coefficients for every pavement, which were then characterized as the proportion between the discharge volume and the inflow volume, estimated toward the conclusion of the precipitation occurrence and comparing to 15 minutes of steady precipitation intensity. The outcomes of the examination affirmed that no surface overflow happened in any of the tests. The discharge coefficients for $\mathrm{CC}$ and $\mathrm{PB}$ went between $0.55-0.75$ during occasions of high precipitation intensity $(98 \mathrm{~mm} / \mathrm{h}$ in 15 minutes $)$, and $0.01-0.12$ during occasions of low precipitation intensity (17 $\mathrm{mm} / \mathrm{h}$ in span 15 minutes). The conclusions likewise demonstrated that higher drainage results were related with higher slopes, and that reused aggregate is a substantial alternative to replace sand and gravel in permeable pavements (Palla et al., 2015, Alsubih et al., 2016).

\section{Design of permeable pavements}

In order for a permeable pavement to work efficiently, the structural and hydrological performances must be taken into account when designing it. Firstly, the structural performance is concerned with the ability of the pavement to carry the load of people and bearing the amount of load exerted by the capacity of vehicles making use of the pavement. Secondly, the hydrological performance involves the ability of the pavement to infiltrate, store and release water in an efficient way for sustainable stormwater management (Hein et al., 2010). Figure 3 shows the process of designing an efficient permeable pavement.

\section{Permeable pavement surface}

Pervious concrete, porous asphalt and permeable, interlocking concrete pavers are the most widely used permeable pavement surfaces. Other choices include plastic and concrete grids, as well as modified soils (artificial media applied to the soil to maintain soil structure and avoid compaction). This paper focuses on 


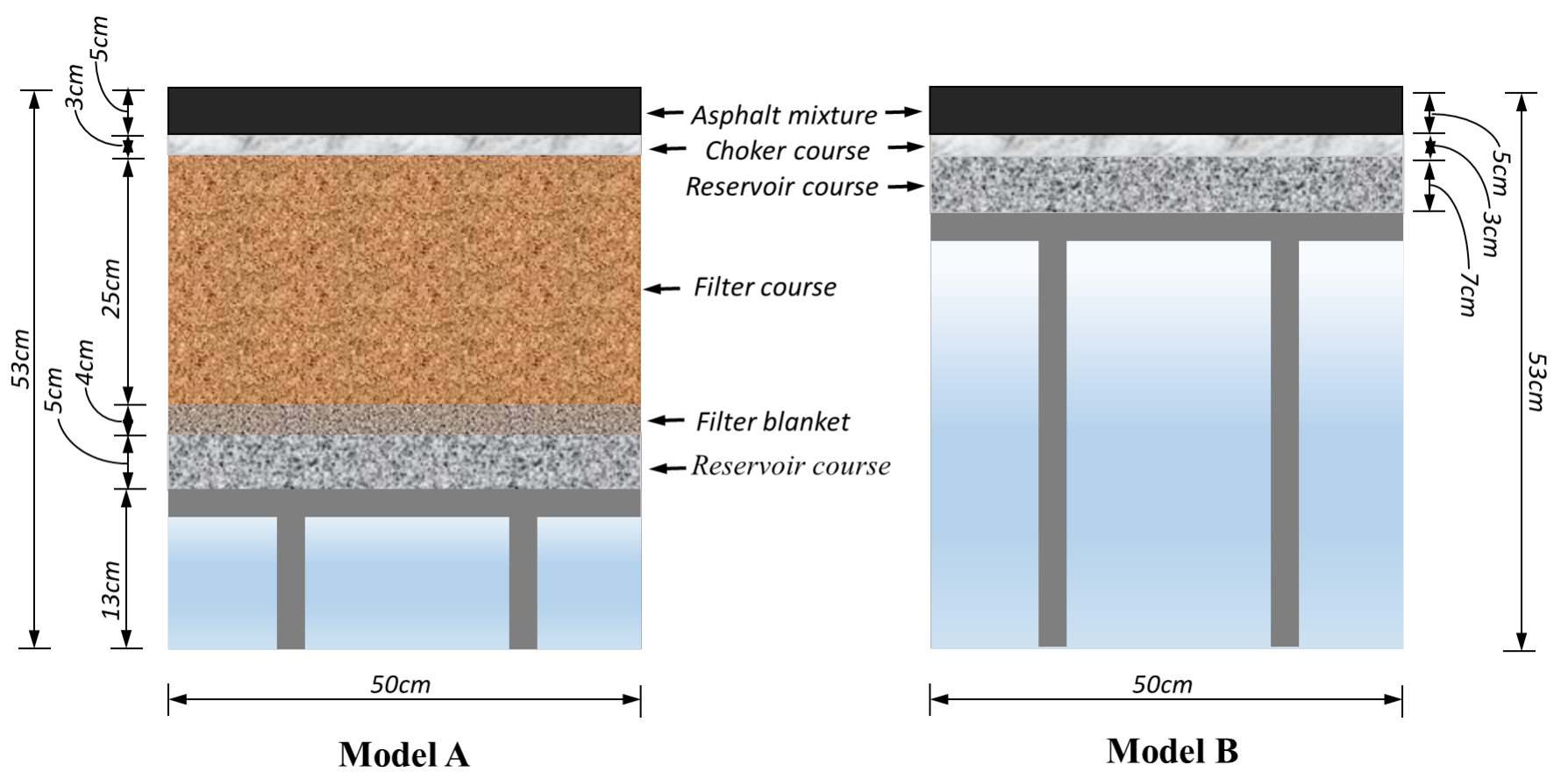

Fig. 2 Permeable Pavements models tested

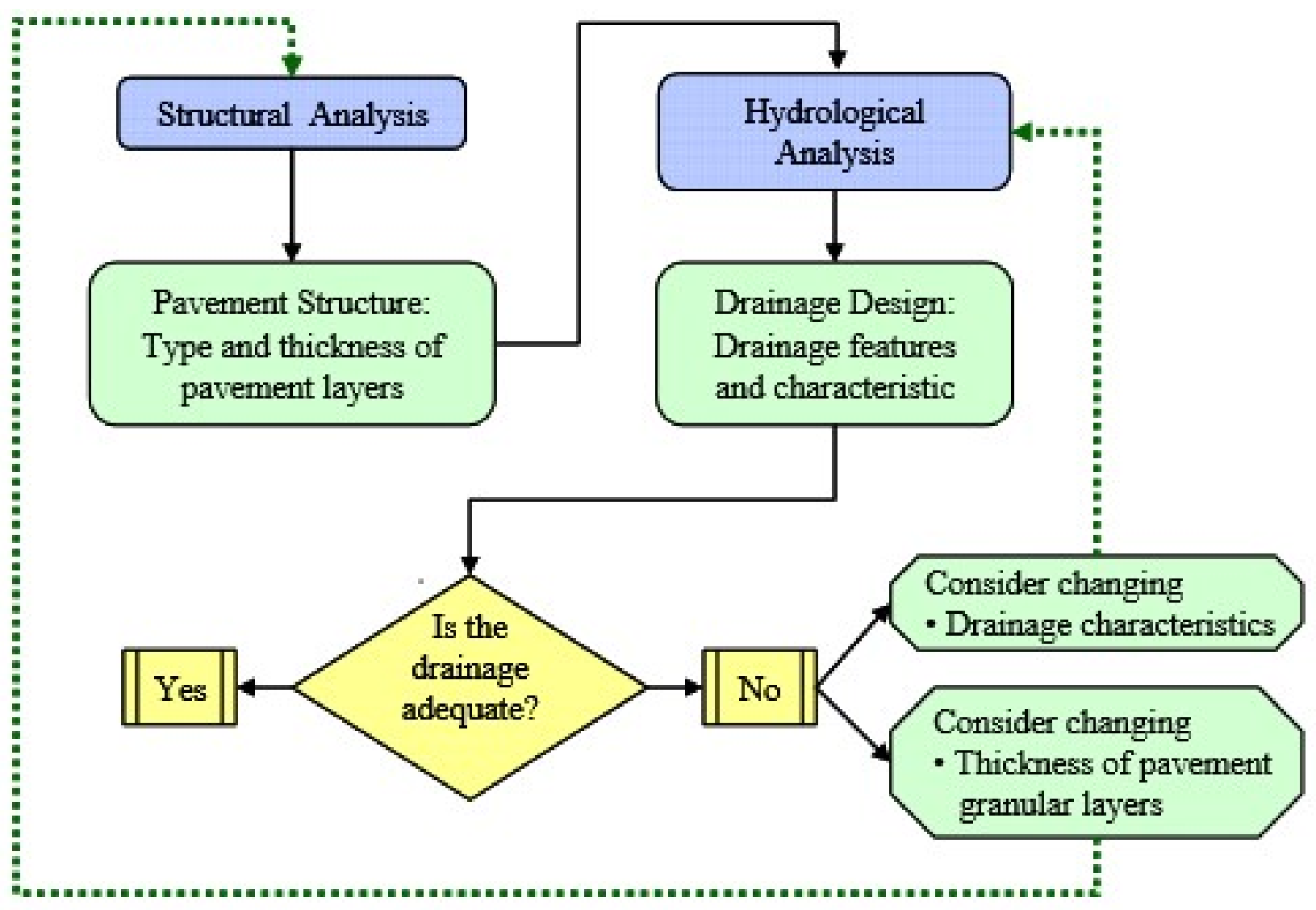

Fig. 3 Schematic of the analysis process (Hein et al., 2010) 
Table 1. Difference between the three types of permeable pavement surfaces (Minnesota-Stormwater-Manual, 2018).

\begin{tabular}{|c|c|c|c|}
\hline Properties & Pervious concrete & Porous asphalt & PICP \\
\hline \multirow[t]{2}{*}{$\begin{array}{l}\text { Typical pavement surface } \\
\text { thickness }\end{array}$} & 5 to 8 inches & $\begin{array}{l}3 \text { to } 4 \text { inches (thicker } \\
\text { for high wheel load } \\
\text { applications) }\end{array}$ & 3 inches \\
\hline & Cast in place & Cast in place & No cure period \\
\hline \multirow[t]{2}{*}{ Construction properties } & Seven-day cure & 24-hour cure & $\begin{array}{l}\text { Manual or mechanical installation of pre- } \\
\text { manufactured units }\end{array}$ \\
\hline & $\begin{array}{l}\text { Must be continuously } \\
\text { covered }\end{array}$ & & \\
\hline Installed surfacing cost & US 3 to $\$ 4 /$ square foot & US \$2/square foot & US 3 to $\$ 4 /$ square foot \\
\hline Overflow & $\begin{array}{l}\text { Catch basin, overflow edge, } \\
\text { elevated underdrain }\end{array}$ & & \\
\hline $\begin{array}{l}\text { Runoff temperature } \\
\text { reduction }\end{array}$ & \multicolumn{3}{|l|}{ Cooling at the reservoir layer } \\
\hline Load bearing capacity & \multicolumn{3}{|c|}{ Handles all vehicle loads with appropriate surface and base/subbase layer material and thickness design } \\
\hline Surface cleaning & $\begin{array}{l}\text { Periodic vacuuming; replace } \\
\text { if completely clogged and } \\
\text { uncleanable }\end{array}$ & & $\begin{array}{l}\text { Periodic vacuuming: replace jointing stones if } \\
\text { completely clogged and uncleanable }\end{array}$ \\
\hline \multirow{2}{*}{ Other issues } & Avoid concentrated de-icers & Avoid seal coating & \multirow{2}{*}{ Avoid winter sanding } \\
\hline & Avoid winter sanding & Avoid winter sanding & \\
\hline
\end{tabular}

the permanent concrete, porous asphalt and permeable concrete pavements that interlocks. Table 1 provides a general description of the properties of the investigated PPS materials.

\section{Permeable pavement sub-base}

The pavements subbase used in permeable pavements is usually consisted of aggregate materials. However, this aggregate material can sometimes be replaced with recycled materials such as recycled concrete, glass, and reclaimed asphalt pavement (RAP). The University of Parma in collaboration with Pisa University has developed and tested a full-scale test track system. The basic idea of this work was to investigate the impact of natural aggregates replacement with RAP on sub-base layers. The research work was divided into two phases: the first that described the materials in the laboratory. The second step is a long-term analysis aimed at researching the efficiency and characteristics of mixtures using non-destructive testing instruments such as the Lightweight Deflectometer (LWD), falling weight deflectometer (FWD), and ground penetrating radar (GPR). The study presented by Montepara et al. (2012) is part of a more comprehensive project aimed at testing mixture efficiency with a high percentage of RAP when used as a sub-base or base layer. To achieve this goal, a pavement test truck was specifically designed and constructed within an asphalt concrete plate plant, attempting to simulate a real pavement that is subjected to heavy vehicle loads moving at low speed. Performance characteristics of unbound layers were monitored by means of FWD + GPR immediately after building, with LWD system, and during time.

The test track consists of two consecutive $30 \mathrm{~m}$ long and $5 \mathrm{~m}$ wide sections consisting of two separate subbase mixture compositions: the first was composed of $100 \%$ natural aggregates while the second was a mixture of $50 \%$ natural aggregates with 50\% RAP. However, composition grading primarily leads to improved compaction of unbound materials, thus expressing its efficiency on site. Because of this, the two separate mixtures were built with the intention of having almost the same grading curve (Fig. 4 Grading Band from the Italian highway management). The laying of $15 \mathrm{~cm}$ of cement-treated base course and $10 \mathrm{~cm}$ of asphalt concrete layer (30 mm NMAS) with 4 per cent asphalt content and 5.5 per cent air voids was completed. Figure 4 displays a vertical and horizontal configuration of the pavement structure with the two distinct subbase layers. It should be noted that letters identified following section identification number refers to the composition of the layers of building. $\mathrm{N}$ refers in particular to subbase produced by natural aggregate only and $\mathrm{R}$ to subbase produced by combining 50 percent of natural aggregates with 50 percent RAP (Montepara et al., 2012). 

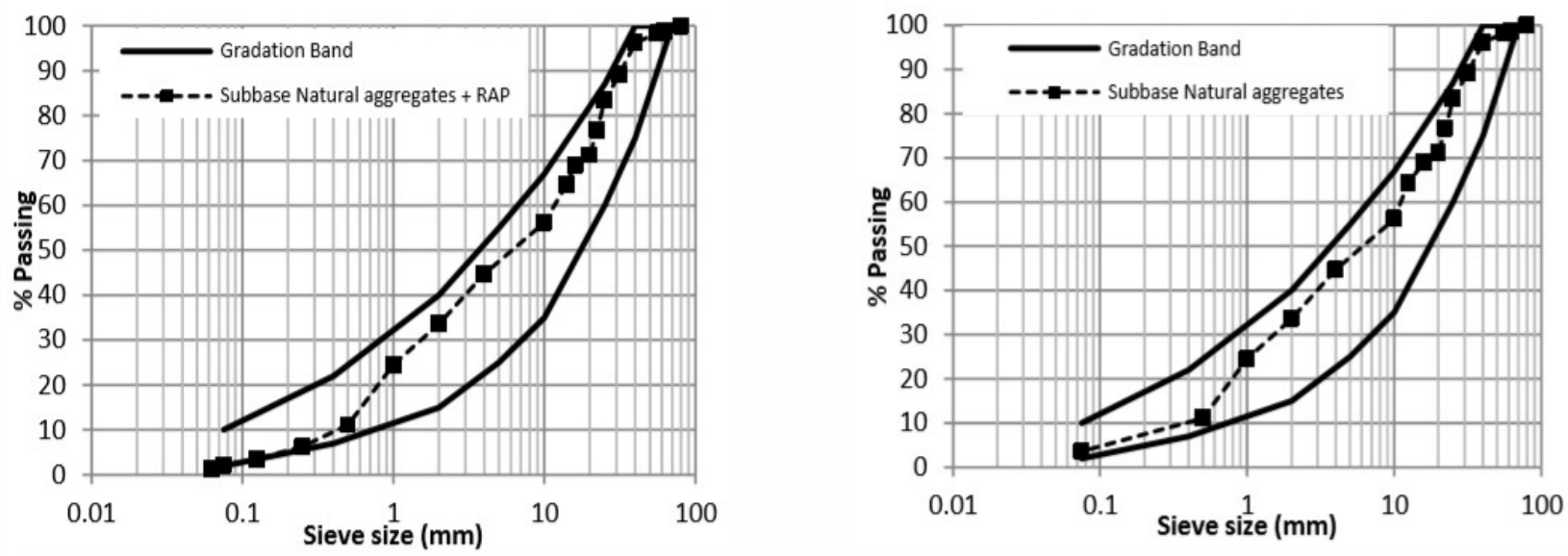

Fig. 4 Grading curve of subbase with only natural aggregates and blended with 50\% RAP (Montepara et al., 2012).

\section{Geotextiles}

Between the laying course and the permeable sub-base, geotextiles are pervious. They are referred informally to as filter fabrics. The size of the geotextile openings or pores will range from 0.02 to 0.002 inches, with the portion of the area in open pores varying to around one third of the surface area. A geotextile layer below the base course will lead to the distribution of the traffic load over soft subgrade in some permeable pavements. As the subgrade attempts to bend the geosynthetic layer under a load is put in tension and its tensile strength properties provide support for the load. Polymeric materials within PPS may be used at two sites, an optional upper geotextile at the laying coarse graded aggregate interface and a lower geotextile as demonstrated in Fig. 5 (Tota-Maharaj et al., 2012).

Pratt et al. (1995) and Bayón et al. (2005) reported that the preservation of oil and related hydrocarbons by geotextile membranes is successful. Thus, the use of geotextiles, such as PPS, within sustainable urban drainage systems (SUDS) involves: erosion protection, filtration and sediment trapping, separation layer, deflection resistance, void forming, bioremediation and pollutant removal.

\section{Underdrains}

Most permeable paving designs would include an underground drain as shown in Fig. 6. Underdrains can also be used during severe weather to prevent stormwater kept from flooding permeable pavement.

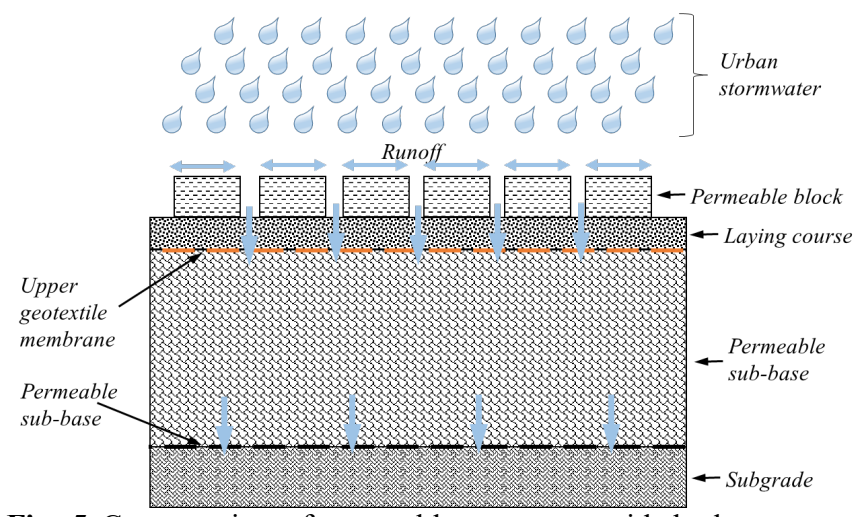

Fig. 5 Cross-section of permeable pavement with both upper and lower layers of geotextile

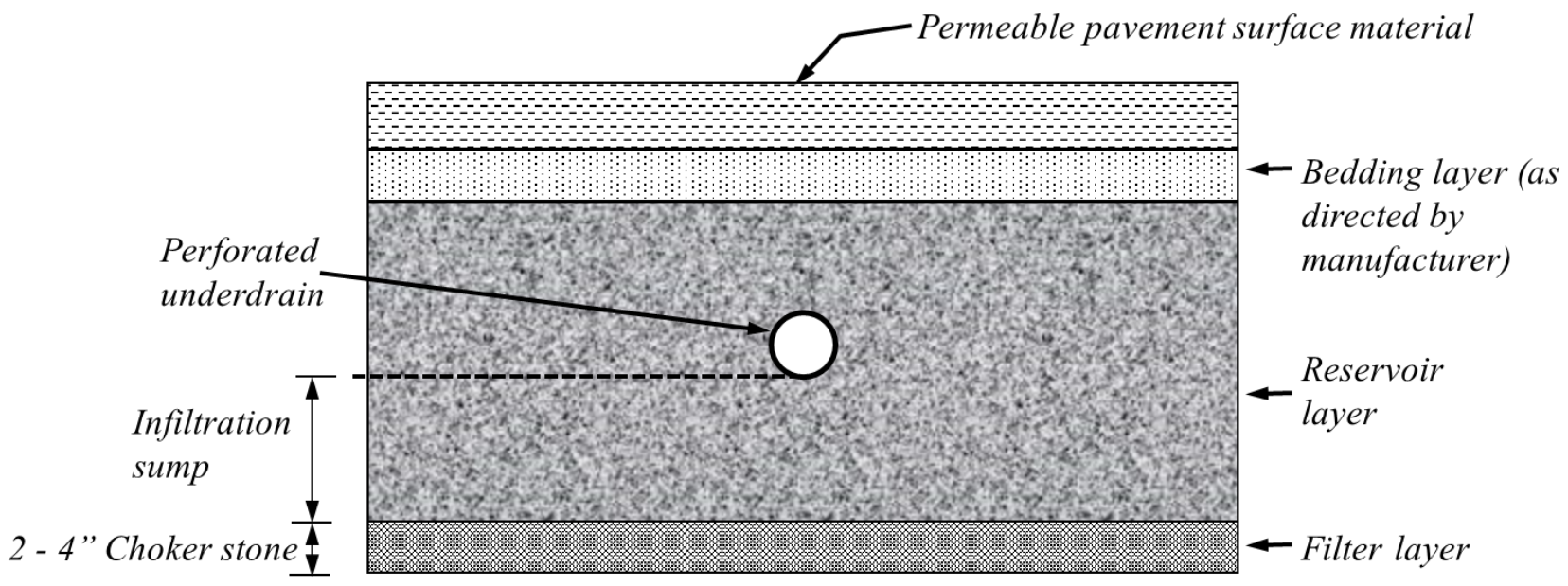

Fig. 6 Cross Section of a permeable pavement design with an underdrain 
This is more required in flat terrains as it can affect proper drainage of permeable pavement designs, so underground drains should have a slope of at least 0.5 per cent. Underdrains from next pipe will be 20 feet or less (Hoffmann et al., 2012). Schedule 40 PVC pipe should be employed and perforated with 3/8-inch perforations in the middle at 6 inches interval, enclosed in a clean sheet and washed No. 57 stone (crushed stone aggregate). Furthermore, the underdrain device will include a flow control to ensure a slow draining of the reservoir layer, which should drain fully within 48 hours.

\section{Clogging}

Permeable Pavements tend to clog up after some time as solid particles are held and accumulated because percolating stormwater conveys with it a range of solids. This issue can be further impacted on by traffic that breaks these into finer particles. The particles occupy and square off void spaces, permitting further collection of fines. On drying, the accumulated particles structure a hard outside layer that seals the voids (Pratt et al., 1995). These procedures diminish infiltration rates, in the long run causing surface flood and ponding when the penetration rates become not exactly the rainfall intensity (Kia et al., 2017). Some studies have clearly observed that clogging usually takes place on the surface or in the upper layer forming the permeable pavement (Kayhanian et al., 2012, Yong and McCarthy, 2013), while others saw that particles are similarly prone to obstruction inside the permeable concrete or underlaying soil (Chopra et al., 2010, Mata and Leming, 2012). These variable discoveries proposed that there is no single area or depth within the permeable pavement where clogging normally happens. Figures $\mathbf{7}$ and $\mathbf{8}$ shows how clogging can take places in different places within the permeable pavement.
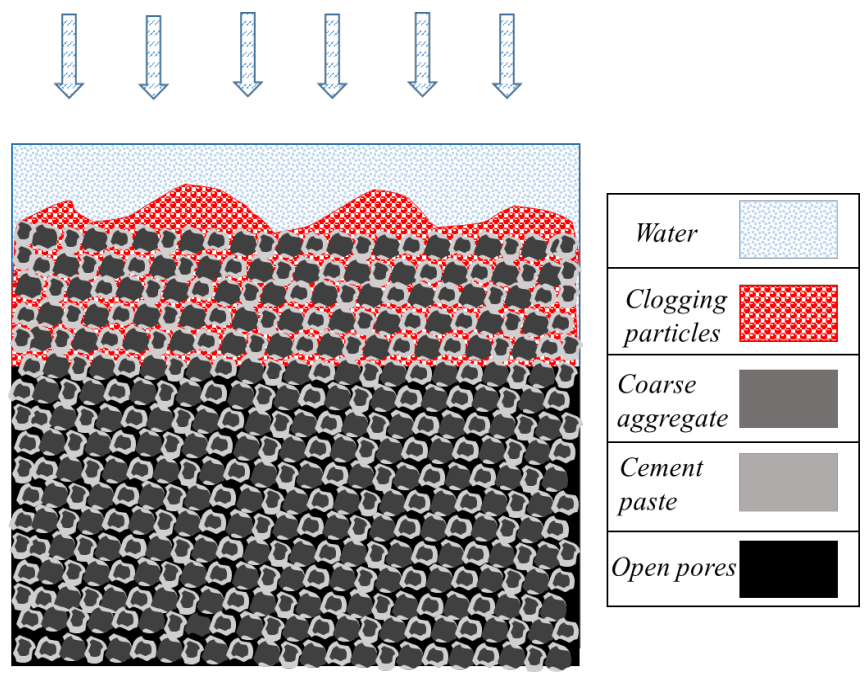

Fig. 7 Clogging on the surface of permeable pavements
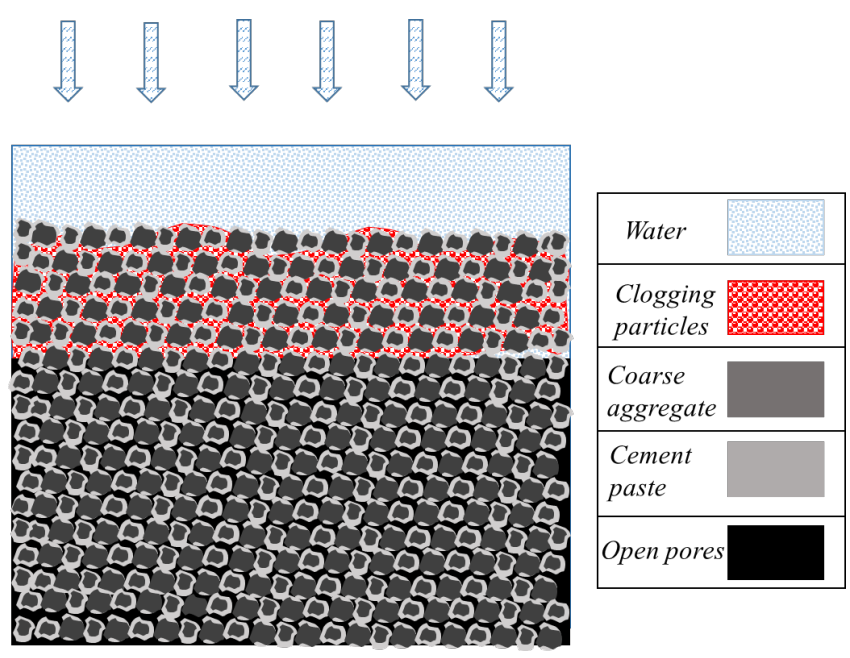

Fig. 8 Clogging throughout the structure of permeable pavement

The prevention of clogging is a major factor at making sure that permeable pavements works efficiently and perfectly. For this to happen, there are simple procedures that needs to be followed (Paver-Search, 2020). Site inspection should be carried out regularly, periodically and after installation of the pavements. This is particularly after heavy rain or storms, for this is the point at which the seepage voids can get clogged with natural debris. Clearing and vacuuming the permeable surface should be carried our periodically (3 months). Street sweepers that have a vacuum and brushes can be used, these are to help clean out the voids in the permeable pavement, and therefore restore permeability. It is also a good practice to apply high pressure hosing of the site after sweeping and vacuuming it thoroughly. Making sure to check that the voids are still well filled with aggregate, and if not, they should be re-filled. Using clean non-friable gravel is the chosen fill material. If needed, damaged permeable pavers should be fixed or replaced, and sections of the whole pavement can be repaired. To maintain the functionality of the pavement, these steps are needed to be carried out.

\section{Long-term quality performance}

The long-term performance of a permeable pavement is largely dependent on how well it is designed and maintained. According to Pervious-Pavement (2011), a permeable pavement is a strong and highly durable material. Areas where the pavement used is properly designed and constructed will last 20-40 years with minimal amount or no maintenance. Awareness with regards to the prevention and gauging of natural effects with respect to any construction is expanding. Recent strategies have been developed to readily comprehend and manage these expanding effects. One of the systems being developed for this purpose was a life cycle 
evaluation (LCA). LCA can recognise opportunities for improving the environmental execution of services at different points in their life cycles, which aids the choice of important environmental performance pointers, helps decision-makers in legislative or nongovernmental associations, for instance characterizing priorities and strategic planning (Guinée et al., 2011).

Furthermore, LCA addresses potential environmental impacts, for example, the utilization of assets and the outcomes of discharges to the environment throughout the duration of the life cycle of an item or service (acquisition of raw materials, production, use, post-use treatment, reusing until definite disposal). LCA studies were made out of four stages: goal and scope; life cycle inventory; impact assessment; and interpretation (BS EN ISO 14040:2006). Li et al. (2018) assessed the life cycle of various sustainable drainage systems: permeable pavements, green rooftops, and wetlands. Likewise, indicators at all phases of the existence cycle (development, operation, maintenance and final disposal) were assessed. The outcomes suggested that the abiotic consumption, acidification potential and the global warming alteration capability of the three drainage systems acquired the best effects in every class: resource depletion, environments and human wellbeing, individually. The effect on human wellbeing is identified with the solid utilized in development, straightforwardly affecting the fatigue of resources. Resource consumption has likewise contributed significantly to biological system harm, while high abiotic exhaustion is for the most part because of the vehicle of materials. The investigation likewise indicated that permeable pavements contributed significantly to flood decrease, with an overflow control pace of $67.5 \%$. Be that as it may, permeable pavements got the most noteworthy abiotic consumption potential, chiefly because of the more prominent utilization of building materials in their structure.

Maiolo et al. (2017) built up a system dependent on the sustainability file to assess the existence pattern of permeable pavements and green rooftops executed in Italy. Figure 9 shows the structure of the permeable pavement utilized in the investigation. The use of the LCA featured that there are significant commitments to the layers made up of common material (sand, gravel), which have an effect due to transportation from the place of origin to the place of execution of the system. Likewise, the existence pattern of polymeric materials is the equivalent for both drainage systems on account of non-renewable sources of energy supply and transport types whose energy class is not especially serious. A confirmation of this reality is that the contribution that carbon dioxide presents has a higher rate than the emissions of the other two gases (methane and

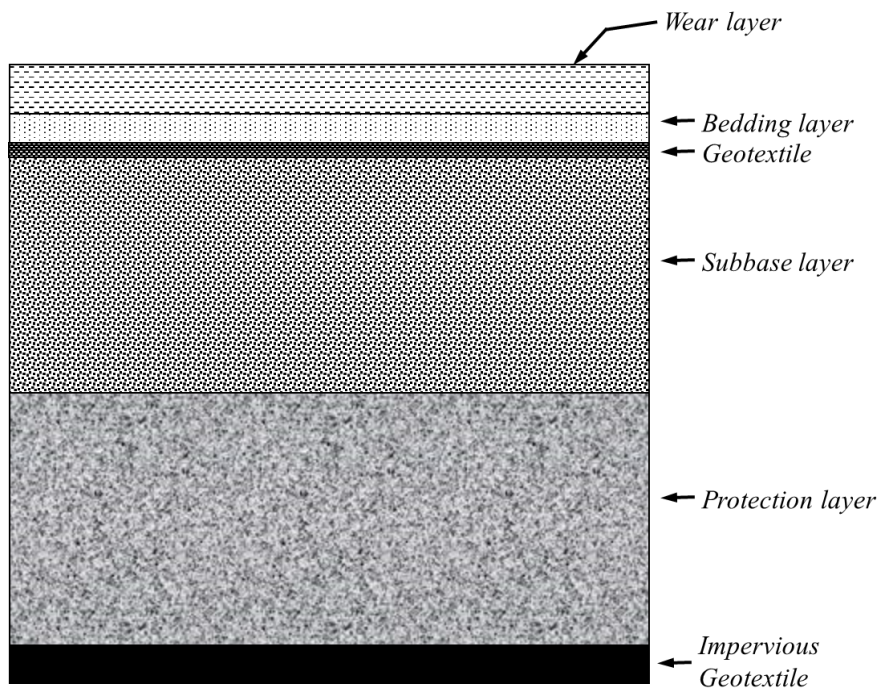

Fig. 9 Structure of the permeable pavement used in the study

dinitrogen monoxide), as shown in Fig. 10. Taking everything into account, the creators express that the examination between the sustainability indices shows that the green infrastructures are technologies that adequately reflect the objective of reducing the environmental impact delivered by waste drainage.

\section{Economic viability and Cost}

The cost of using a permeable pavement section is ordinarily higher than cost of an ordinary pavement. This is essentially because of the way that the permeable pavement is thicker to permit adequate water storage and to give adequate basic ability to overcome vehicle loading. Be that as it may, cost correlation of the whole permeable pavement framework contrasted with a regular pavement shows a sensible cost examination when considering the decrease or end of catch basins, underground piping, seepage ditches and stormwater management ponds required for conventional structures.

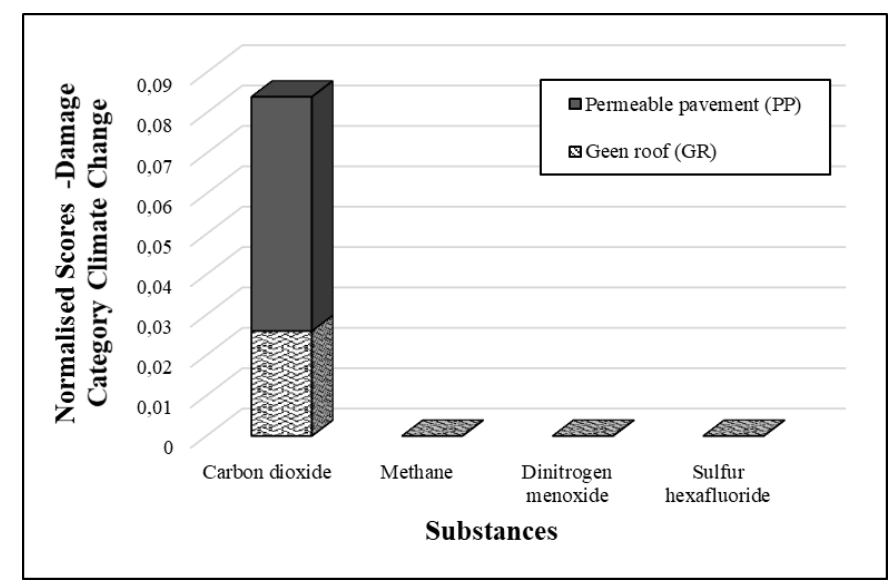

Fig. 10 Gases emitted during the life cycle of Permeable pavement (PP) and green roof (GR) 
There are likewise different points of interest, for example, decreased downstream erosion, diminished pollutant loads, less impact on existing stormwater infrastructure, and so forth. The financial benefits of permeable pavements can be acknowledged when life cycle cost examination is performed. Notwithstanding, because of the absence of huge scope testing, long haul execution information, and development and maintenance cost information, life cycle cost investigation has been difficult to perform, requiring a few suspicions. Wang et al. (2010) contrasted permeable pavement systems and traditional stormwater management systems utilized at the road shoulders. Permeable pavements decreased life cycle costs by up to $30 \%$.

In another investigation, directed by Terhell et al. (2015), in light of information acquired from a few organizations, it was discovered that permeable pavements can set aside to US\$64,649, considering establishment expenses, and US $\$ 3,788,856$ considering stormwater treatment benefits over 25 years for $1 / 2$ acre of land zone contrasted with traditional pavement. The decrease in the expense of development is ascribed for the most part to the way that permeable pavements do not require side drains, overlays, etc.

\section{Carbon Footprint}

In the first place, permeable pavements help to spare energy by moderating stormwater runoff. This design comprises of various voids, bringing about a honeycomb-like structure. This porous nature permits stormwater to deplete down through a several inches of material where it gradually infiltrates into the soil and in the long run renews the water table. The water can likewise be drained into capacity tanks where it is held until utilized on a property for water system and other non-consumable purposes. An additional advantage: the water is normally separated as it permeates through the system, expelling numerous ecological contaminants and pollutants, including metals (Priebe, 2009).

Conversely, where traditional permeable pavement is utilized, foundations put resources into offices to oversee stormwater overflow, for example, get basins, culverts, storm channels, detention lakes and such, and energy is then used to pass on the water and reintroduce into the earth. A NRDC Technical Report (A Clear Blue Future) takes note of that the province of California utilizes 19 percent of its power and 33 percent of nonpower-plant natural gas for passing on and treating water. A portion of this cost could be stayed away from with pervious surfaces, which can practically dispose of stormwater overflow when appropriately structured. James (2013) demonstrated that traffic on highways is a significant wellspring of pollutants and that these are charged to waterways and streams when precipitation happens. A review by the Forth River Purification Board shows that over $14 \%$ of unsuitable river water is expected to stormwater overflow in urban zones. The nature of the water depleted by permeable and ordinary pavements was looked at and the outcomes got are appeared in Table 2. It is conceivable to see that the permeable pavement has incredible support during the time spent in the treatment of stormwater, having the option to be an extraordinary facilitator in the advancement of maintainable seepage frameworks.

The use of recycled materials in the construction of permeable pavements plays a major part in reducing the carbon footprint, this can be done by installing these recycled materials such as plastic, rubber, glass and recycled concrete into each different layer of the pavement, and then carrying tests and comparing different materials with each other to get to know which materials are best to use and what recycled materials work best together to provide the most efficient yet sustainable pavement of them all.

\section{Methodology}

The carbon content of permeable pavements that was tested in this research project is anticipated to reduce the carbon footprint by utilising low carbon materials in its production. Material sampling in preparation for the mechanical performance of the proposed pavement was carried oud in accordance with ASTM C140 - 11a. All construction and environmental materials tests were conducted at the university of the West of England, Bristol (UWE Bristol) Civil and Environmental Engineering Cluster, Concrete Laboratory at Frenchay Campus, Bristol, United Kingdom.

Table 2. Reduction of pollutants when using permeable pavements compared to when using conventional pavements (James, 2013)

\begin{tabular}{lc}
\hline Parameter & Reduction of Pollutants (\%) \\
\hline Suspended Solids & $80-99$ \\
Phosphorus & $65-71$ \\
Nitrogen & $75-85$ \\
Total organic carbon & 82 \\
Lead & $50-98$ \\
Zinc & $62-99$ \\
Chrome & $87-88$ \\
Cadmium & $0-34$ \\
Copper & 42 \\
Heavy metals & $90-99$ \\
Biochemical oxygen & $80-83$ \\
demand & 88 \\
Chemical oxygen & 95 \\
demand & $97-98$ \\
Hydrocarbons & \\
Oil & \\
\hline
\end{tabular}


Table 3. Concrete mix for Conventional blocks

\begin{tabular}{lcccc}
\hline & \multicolumn{3}{c}{ Type of Blocks } \\
\cline { 2 - 5 } Material & Conventional blocks & $\begin{array}{c}\text { Recycled Glass } \\
\text { blocks }\end{array}$ & $\begin{array}{c}\text { Recycled Grit } \\
\text { blocks }\end{array}$ & Recycled Rubber blocks \\
\hline Cement (g) & 1680 & 1680 & 1680 & 1680 \\
Water (ml) & 800 & 800 & 800 & 800 \\
Recycled grit (g) & 1638 & 819 & 2520 & 2319 \\
Recycled glass (g) & - & 1260 & - & - \\
Recycled rubber (g) & - & - & - & 1260 \\
Sand (g) & 882 & 441 & - & 441 \\
$4 / 10$ mm stones & 4700 & 4700 & 4700 & 4700 \\
\hline
\end{tabular}

\section{Pavement design and materials}

Four samples of low carbon permeable pavements were designed and constructed by the authors in accordance with CD 226. The Four samples of pavements had concrete permeable blocks with varying mix compositions, sub-base and bedding aggregates. Four different materials were used when designing the pavements (conventional mix of $250 \mathrm{~mm}$ depth, recycled Glass mix of $250 \mathrm{~mm}$ depth, recycled Grit mix of $250 \mathrm{~mm}$ depth and recycled Rubber mix of $250 \mathrm{~mm}$ depth). The subbases were used as $250 \mathrm{~mm}$ as it usually ranges from $150-300 \mathrm{~mm}$.

All four (4) samples had the same size and were held in wooden moulds of $185 \mathrm{~mm}$ x $175 \mathrm{~mm}$ x $500 \mathrm{~mm}$. Each sample had permeable blocks, bedding aggregate, sub-base, sub-grade which is native soil and a drainage hose that passes the stormwater out of the subgrade layer. All four samples had concrete blocks made from recycled materials as the surface of those pavements. The ratio of the mixes used were 1:2:3, with 1-part cement, 2 parts sand and 3 parts aggregate respectively. Furthermore, the bedding aggregate was composed of $50 \mathrm{~mm}$ depth, while the bedding layer was different in every pavement sample. Natural sand was used as the conventional construction material between the gaps of the pavements at a depth of $70 \mathrm{~mm}$., which is due to its availability.

\section{Permeable concrete blocks materials}

Four different mixes were adopted to manufacture the low-carbon blocks for making up of the surface of the permeable pavements. Changes made to the blocks in each mix were carried out by the substitution of natural sand with recyclable materials in every different mix by weight (Table 3). For the first mix, a conventional mix was used. The second mix was developed using crushed glass to replace part of the natural sand and grit used in the Conventional mix, while for the third mix, all the sand was replaced with recycled grit. For the final mix rubber was used within the mix, but extra $1500 \mathrm{~g}$ of grit were used as the rubber would not bind. Note that only $4 / 10 \mathrm{~mm}$ aggregate stones were used so they can fit into the molds.

These developed blocks were made in compliance with ASTM C936/C936M-13. As such, forty-eight permeable concrete blocks were produced, twelve of each mix with different dimensions as shown in Table 4. Two blocks each were placed in a single mold of Styrofoam with polystyrene separators to prevent confusion of mixes and then put on a vibrating table to make sure no voids are left within the blocks (Figs. 11-13)

Table 4. Dimensions of blocks

\begin{tabular}{lccc}
\hline Pavement block type & $\begin{array}{c}\text { Length } \\
(\mathrm{mm})\end{array}$ & $\begin{array}{c}\text { Width } \\
(\mathrm{mm})\end{array}$ & $\begin{array}{c}\text { Depth } \\
(\mathrm{mm})\end{array}$ \\
\hline Pavement block & 75 & 50 & 50 \\
Pavers & 75 & 50 & 50 \\
Absorption test & 100 & 100 & 50 \\
Compression test & &
\end{tabular}

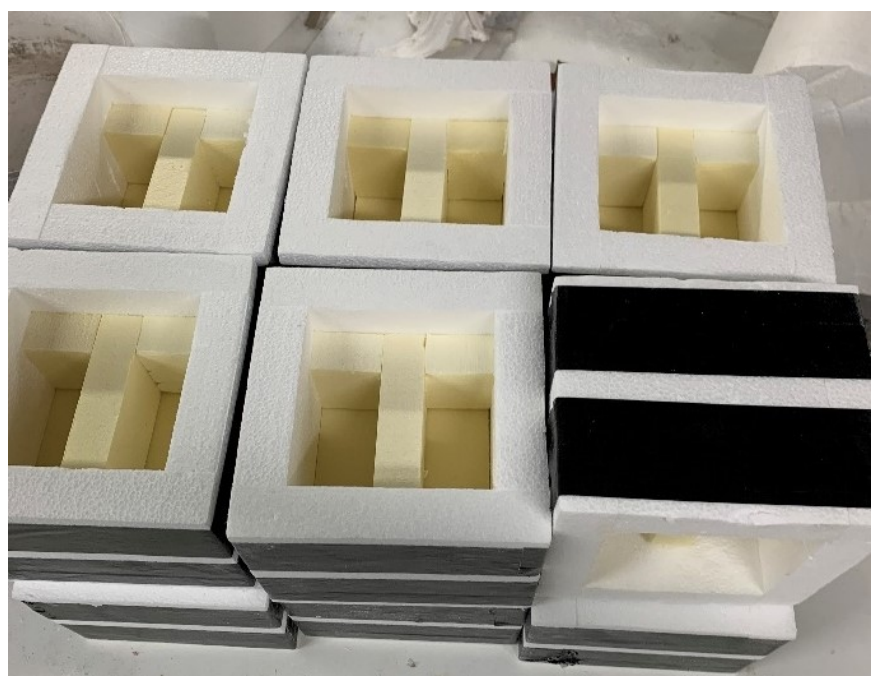

Fig. 11 Styrofoam molds with polystyrene separators and tape to prevent breakdown of molds 


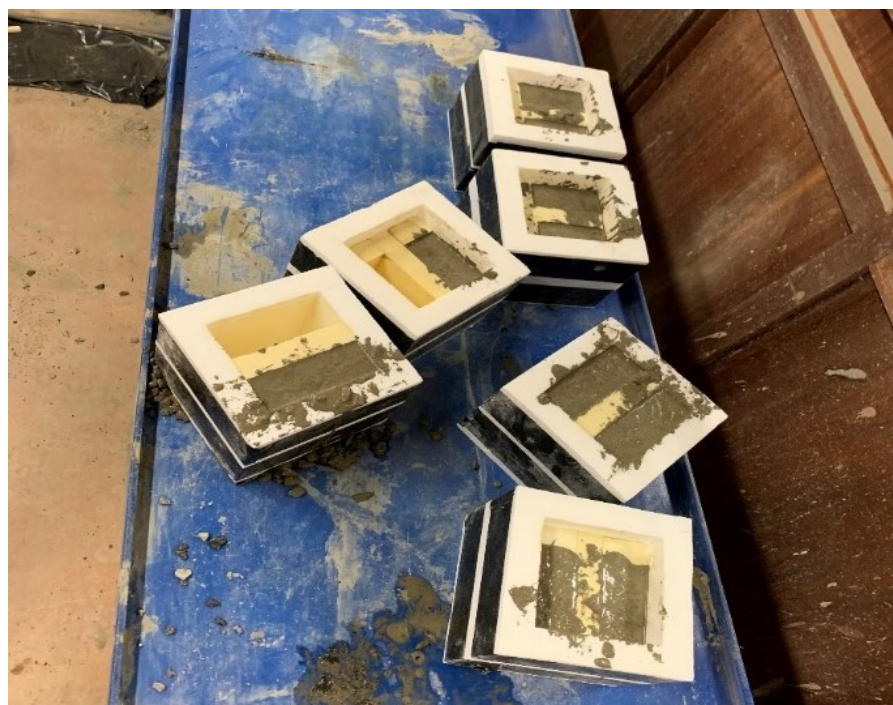

Fig. 12 Molds placed on vibrating table

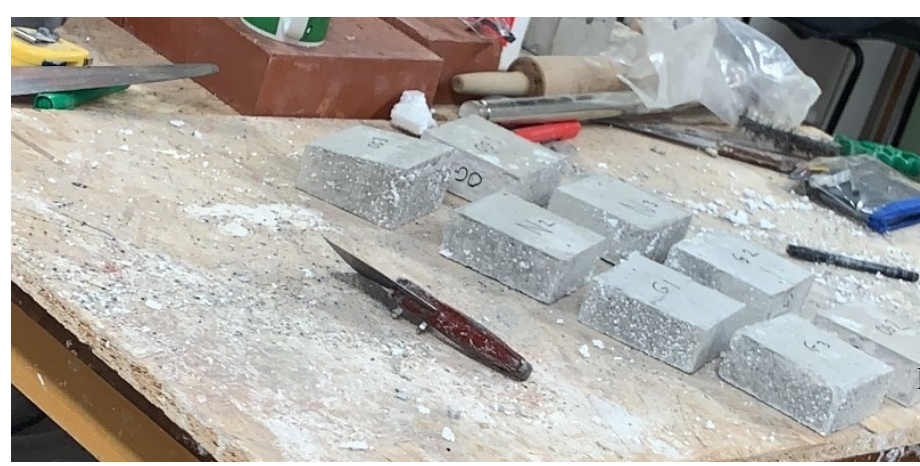

Fig. 13 Pavement blocks used for compression tests

\section{Experimental Procedure}

Three laboratory tests were carried out with two carried out on the concrete blocks (compression test and water absorption test), while the infiltration test was carried out on the different pavement samples.

\section{Absorption Test}

A water absorption test is a tool used to assess water absorption by calculating the amount of water that penetrates when immersed into concrete samples. The lower the absorption the better the results as high water absorption levels lead to deterioration because of thawing and periodical freeing during cold seasons (ASTM C642-13). For the absorption test, twelve blocks were tested, three of each type, the test was carried out as shown in Fig. 14. All the initial weights of the blocks were measured after striking them from their molds (Fig. 15), and then soaked in a water tub for twenty-four hours. Thereafter, the saturated weight of the blocks was weighed after removing the blocks out of the water.

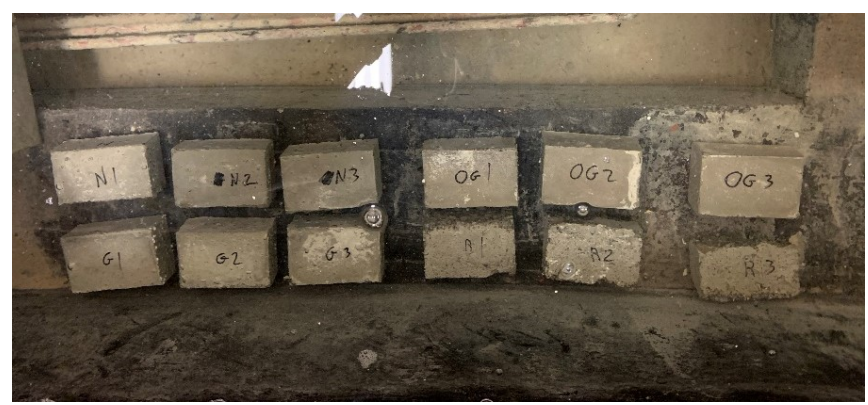

Fig. 14 Pavement blocks in tub filled with water

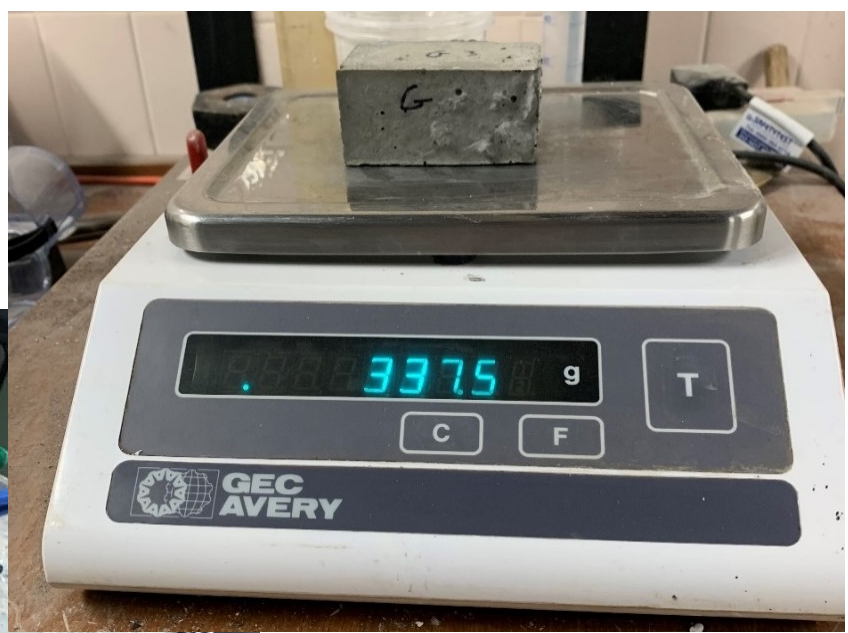

Fig. 15 Pavement biocks weighed Concrete laboratory, UWE Bristol

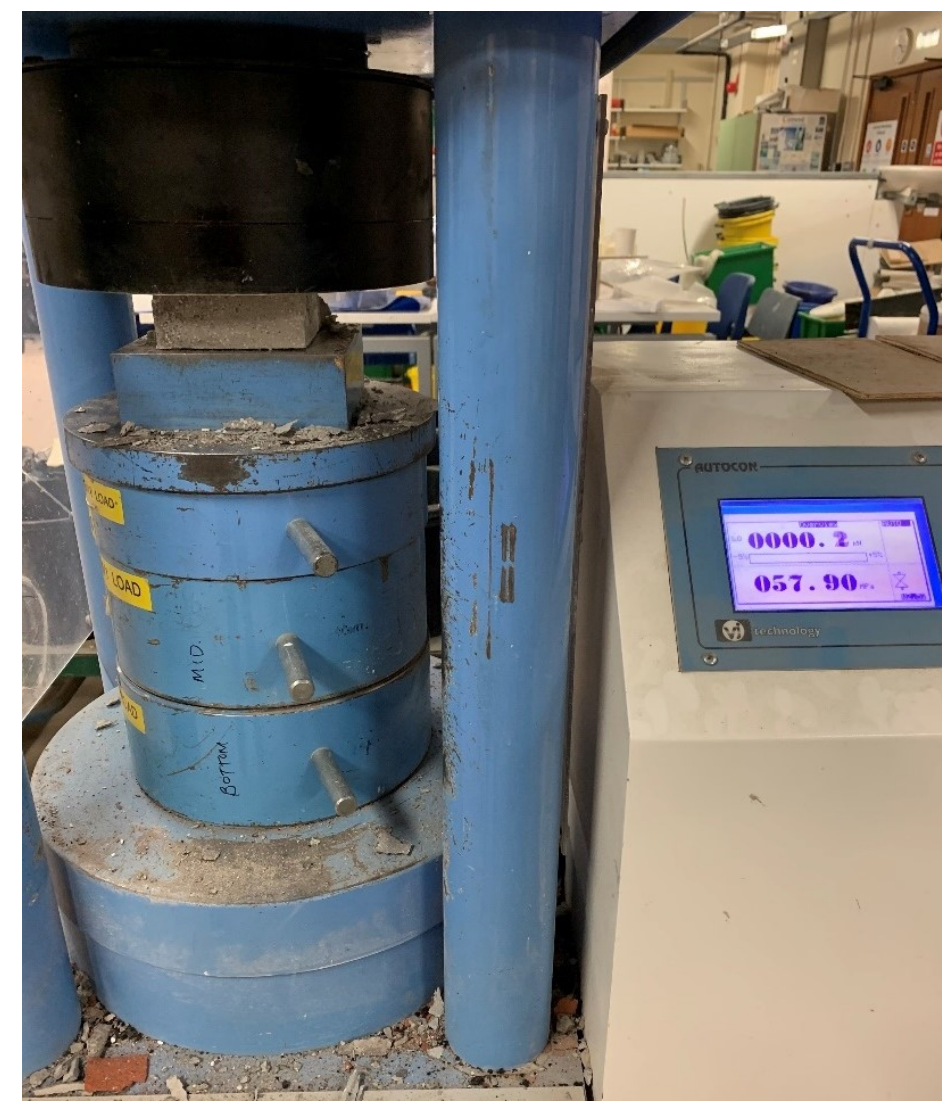

Fig. 16 Compression test set up concrete laboratory, UWE Bristol 


\section{Unconfined Compression strength (UCS) Test}

The unconfined compression strength (UCS) test demonstrates how maximum concrete strength can be accomplished in ideal conditions. In the hardened state the compression test records the tested concrete strength. Concrete field samples are prepared, cured and tested in compliance with ASTM C140-11a. Twelve concrete block samples were tested for their compressive strength, three of each type of mix as shown in Fig. 16. The average compressive strength value of block from each type of mix was established, which was expected not less than 40Mpa (ASTM C936/C936M-13). The samples were tested by placing the centre of thrust of the steel vertically with the centroid of their bearing surfaces. The recorded values were taken at which the cubes failed. Compressive tests were done on paving samples $(100 \mathrm{~mm} \times 100 \mathrm{~mm} \times 50$ $\mathrm{mm}$ ), cured for a duration of 56 days.

\section{Infiltration Test}

Three different samples of permeable pavements were constructed instead of four, this was due to the failure of rubber blocks while undergoing a UCS test and the high levels of absorption during the absorption test. This test was carried out by passing a fixed volume of water through the pavement's samples, and recording the time taken to discharge fixed amount of water. The pavements were constructed with six block pavers, and perforating the moulds with equally sized circles at the bottom with an attached water hose to the pavements to allow the exit/recording of water (effluent) volume from the pavements (Fig. 17).

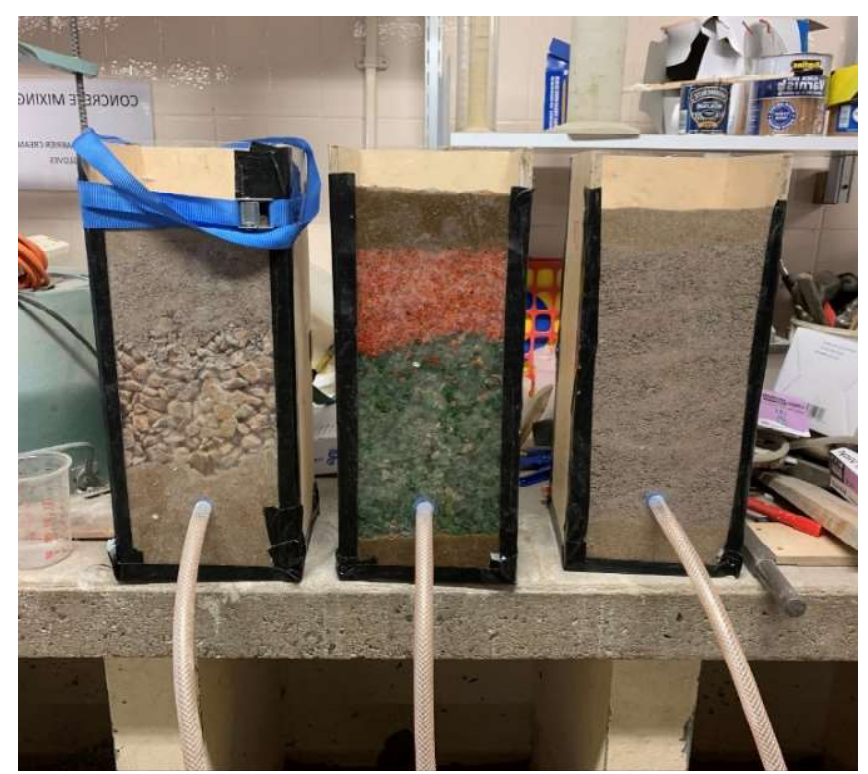

Fig. 17 Infiltration test set-up concrete laboratory, University of the West of England, Bristol (UWE Bristol)
The three samples illustrated in Fig. 17 from left to right are (i) A Conventional pavement mix, (ii) Recycled Glass Mix and (iii) a Recycled Grit Mix. Figure 18 shows the placement of the permeable pavers on the surface of the permeable pavements.

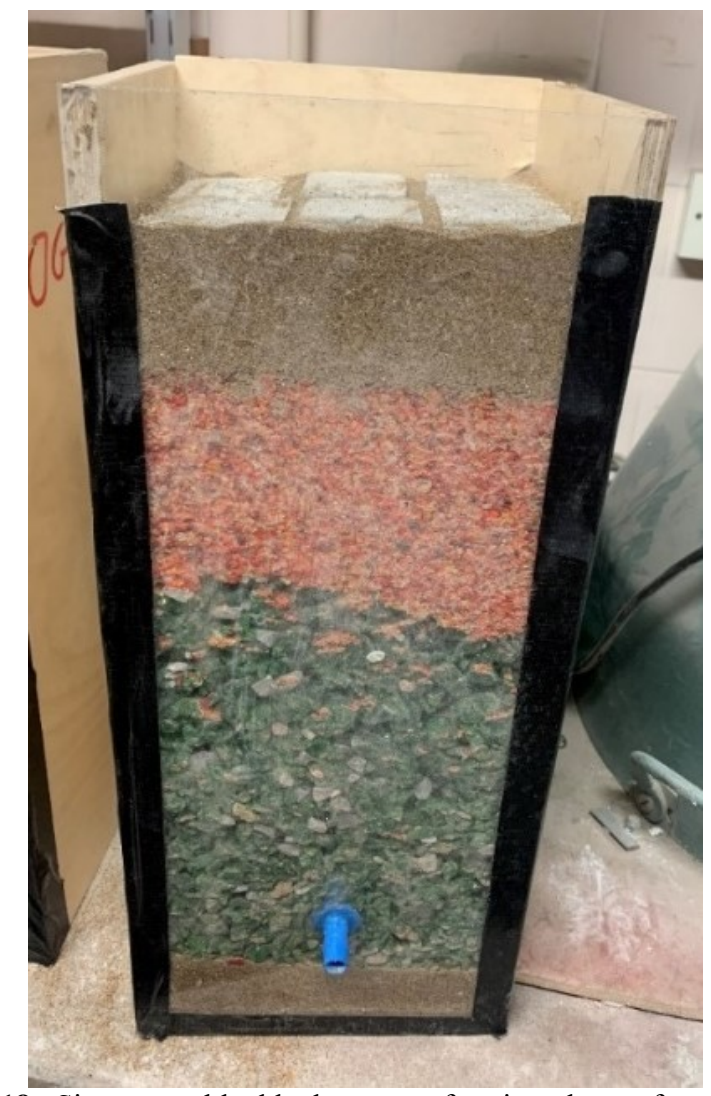

Fig. 18: Six permeable block pavers forming the surface of the permeable pavement system (PPS)

\section{Results and Discussion}

\section{Absorption Test Results}

Concrete blocks for each sample were tested in accordance with ASTM C642 - 13. The value of the water absorption rate of each block was calculated by dividing the difference between the saturated and dry weight over the dry weight. Equation 1 used for the calculation of water absorption is shown below. Table 5 shows the values of the average absorption rate for each type of mix.

Water Absorption $=\frac{W_{s}-W_{d}}{W_{d}} \times 100$

Table 5 and Fig. 19 shows that the mix where recycled grit was used had the lowest water absorption rate with the recycled glass possessing a slightly higher values of absorption. This makes the use of recycled grit and recycled glass more efficient in getting rid of water 
Table 5. Absorption rate for each sample

\begin{tabular}{|c|c|c|c|}
\hline $\begin{array}{l}\text { Pavement } \\
\text { Sample }\end{array}$ & $\begin{array}{l}\text { Dry weight, } W_{d} \\
(\mathrm{~g})\end{array}$ & $\begin{array}{c}\text { Saturated } \\
\text { weight, } \mathrm{W}_{\mathrm{s}}(\mathrm{g})\end{array}$ & $\begin{array}{c}\text { Absorption } \\
(\%)\end{array}$ \\
\hline \multicolumn{4}{|c|}{ Normal Mix } \\
\hline 1 & 319.5 & 330.5 & 3.3 \\
\hline 2 & 330.2 & 342.8 & 3.7 \\
\hline 3 & 330.5 & 343.0 & 3.6 \\
\hline Average & 326.7 & 338.8 & 3.5 \\
\hline \multicolumn{4}{|c|}{ Recycled Glass Mix } \\
\hline 1 & 344.6 & 354.8 & 2.9 \\
\hline 2 & 326.2 & 336.3 & 3.0 \\
\hline 3 & 325.2 & 338.6 & 4.0 \\
\hline Average & 332.0 & 343.2 & 3.3 \\
\hline \multicolumn{4}{|c|}{ Recycled Grit Mix } \\
\hline 1 & 341.4 & 351.3 & 2.8 \\
\hline 2 & 344.0 & 356.0 & 3.4 \\
\hline 3 & 331.0 & 342.7 & 3.4 \\
\hline Average & 338.8 & 350.0 & 3.2 \\
\hline \multicolumn{4}{|c|}{ Recycled Rubber Mix } \\
\hline 1 & 192.8 & 212.6 & 9.3 \\
\hline 2 & 191.1 & 209.2 & 8.7 \\
\hline 3 & 170.1 & 190.7 & 10.8 \\
\hline Average & 184.7 & 204.2 & 9.6 \\
\hline
\end{tabular}

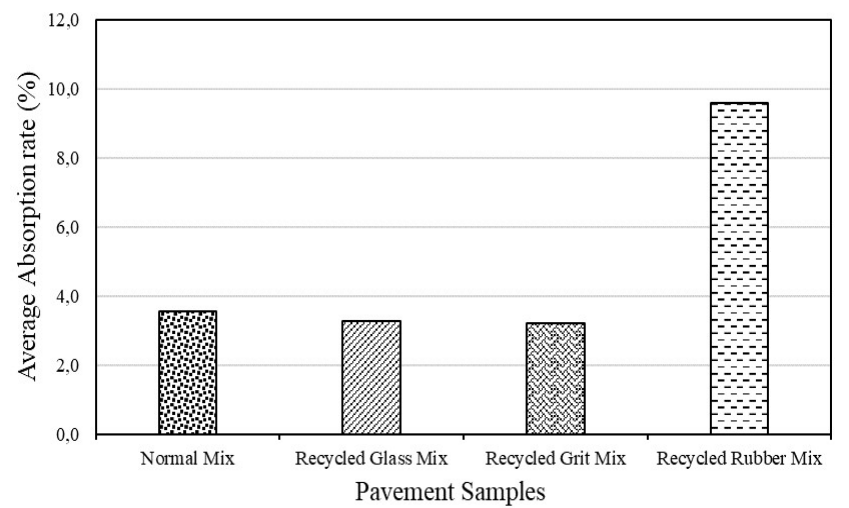

Fig. 19 Average absorption rate of every type of sample mix

for preventing thawing and water freezing in cold seasons. Moreover, the blocks where recycled rubber was used had a very high rate of absorption compared to other types of mixes, this makes the rubber blocks unsafe to use in permeable pavements. Evangelista and De Brito (2010) investigated the durability performance of concrete with two different fine aggregates. The concrete made with fine recycled aggregate (FRA) was compared to concrete made with fine natural aggregate (FNA). Both samples were tested for water absorption with immersion and water capillarity.

Compressive strength $=\frac{\text { Maximum compressive load }}{\text { Area of cube }}$

The results came out to be that FRA has a $46 \%$ higher water absorption rate than FNA when tested by immersion, it was also discovered that FRA's resistance to capillarity was more unfavourable than by immersion, this can be seen in Table 6 and Fig. 20. Overall, this investigation has shown that FRA has a higher water absorption than FNA, this shows that not all recycled materials work better when used in partial replacements in the construction of concrete. Where RC is the reference concrete, $\mathrm{C}^{* *} \mathrm{R}$ is the concrete mix with the \% replacement of FNA by FRA (Evangelista et al., 2010).

\section{Unconfined Compression Test (UCS) Results}

The values of the maximum UCS values was obtained and recorded in kilonewtons $(\mathrm{kN})$. The UCS value for each block was calculated by dividing the maximum load over the cross-sectional area of each block using Eq. 2 in accordance with ASTM-C140-11a. Table 7 shows the UCS values for every type of concrete mix.

Table 6. Water absorption by immersion (48) amended for this study Pavement Water absorption parameters Block $\mu(\%) \quad \sigma(\%) \quad C v$ $\Delta(\%)$

\begin{tabular}{lcccc}
\hline $\mathrm{RC}$ & 11.3 & 0.11 & 0.0097 & - \\
$\mathrm{C} 30 \mathrm{R}$ & 130 & 0.22 & 0.0167 & 16.8 \\
$\mathrm{C} 100 \mathrm{R}$ & 16.5 & 0.32 & 0.0194 & 48 \\
\hline
\end{tabular}

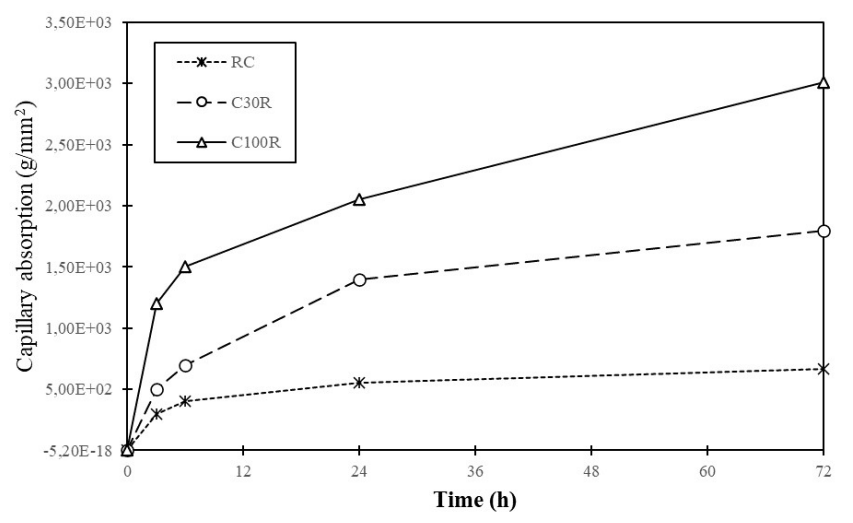

Fig. 20 Capillary water absorption (Evangelista et al., 2010)

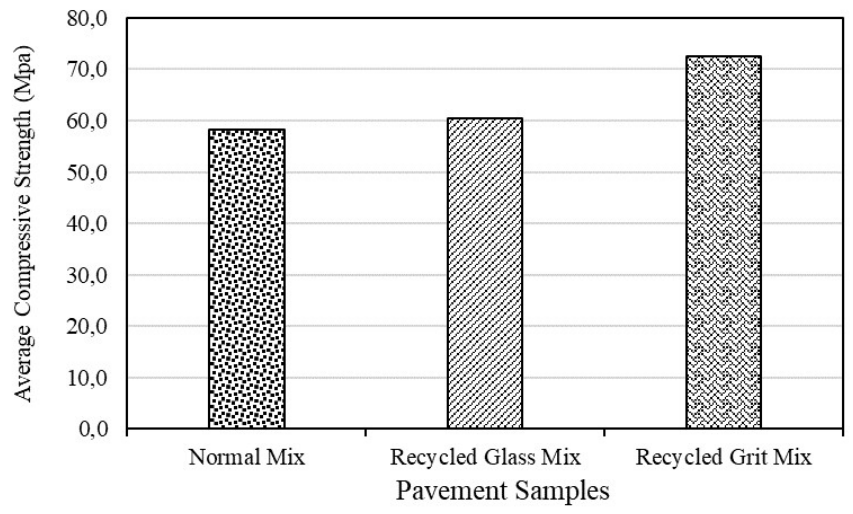

Fig. 21 Average compressive strengths of every type of sample mix 
Table 7. Unconfined Compressive Strength Results of blocks

\begin{tabular}{|c|c|c|c|c|}
\hline Pavement Sample & $\begin{array}{c}\text { Dimensions of cube } \\
(\mathrm{mm} \times \mathrm{mm} \times \mathrm{mm})\end{array}$ & Area of cube $\left(\mathrm{mm}^{2}\right)$ & Failure load $(\mathrm{kN})$ & $\begin{array}{l}\text { Compressive } \\
\text { Strength (Mpa) }\end{array}$ \\
\hline \multicolumn{5}{|c|}{ Conventional Mix } \\
\hline 1 & $100 \times 100 \times 50$ & 10000 & 594.0 & 59.4 \\
\hline 2 & $100 \times 100 \times 50$ & 10000 & 613.0 & 61.3 \\
\hline 3 & $100 \times 100 \times 50$ & 10000 & 541.0 & 54.1 \\
\hline Average & & & 582.7 & 58.3 \\
\hline \multicolumn{5}{|c|}{ Recycled Glass Mix } \\
\hline 1 & $100 \times 100 \times 50$ & 10000 & 597.0 & 59.7 \\
\hline 2 & $100 \times 100 \times 50$ & 10000 & 579.0 & 57.9 \\
\hline 3 & $100 \times 100 \times 50$ & 10000 & 638.0 & 63.8 \\
\hline Average & & & 604.7 & 60.5 \\
\hline \multicolumn{5}{|c|}{ Recycled Grit Mix } \\
\hline 1 & $100 \times 100 \times 50$ & 10000 & 749.0 & 74.9 \\
\hline 2 & $100 \times 100 \times 50$ & 10000 & 720.0 & 72.0 \\
\hline 3 & $100 \times 100 \times 50$ & 10000 & 708.0 & 70.8 \\
\hline Average & & & 725.7 & 72.6 \\
\hline
\end{tabular}

The results in Table 7 and Fig. 21 shows that the values of the average compressive strength of the blocks with recycled grit mix achieved the maximum UCS value $72.6 \mathrm{Mpa}$. While the cubes with the lowest values of average compressive strength were the blocks composed of the conventional mix. This shows that the use of recycled materials in the mixes of the pavements can lead to having higher durability and strength to overcome the amount of load exerted on the permeable pavements, as well as using low-carbon materials is a more sustainable option to use in pavements. The blocks with the rubber were too brittle and could not bear the load exerted by the compressive test machine, so no results could have been taken and compared to other types of mixes. Salah El-Deen et al. (2004) performed laboratory and factory experiments for the manufacture of paving blocks using cement-dust as a replacement for cement. The goal of the research was to reduce the costs of the manufactured paving blocks by reducing the amount of cement used in the concrete mix. They concluded that cement-dust substitution of 30 per cent could be used to produce paving blocks. Poon et al. (2002) conducted an experiment to examine the viability of using recycled concrete aggregates in paving block manufacture. They concluded that replacing coarse and natural aggregates with recycled concrete aggregate would exceed 50 per cent without a recordable reduction in paving blocks 'compressive power. The quality of the paving blocks produced has also been satisfactory. Poon and Chan (2006) submitted a study in conjunction with recycled concrete aggregate to use the crushed clay brick as a coarse aggregate. Results showed that adding the crushed clay brick reduced paving blocks density, compressive strength, and tensile strength.

Table 8. Infiltration test results for each mix

\begin{tabular}{|c|c|c|c|c|}
\hline Pavement Sample & $\begin{array}{l}\text { Volume of influent } \\
\text { stormwater (ml) }\end{array}$ & $\begin{array}{l}\text { Volume of effluent } \\
\text { stormwater (ml) }\end{array}$ & $\begin{array}{l}\text { Time taken } \\
\text { to drain }(\mathrm{s})\end{array}$ & $\begin{array}{l}\text { Infiltration rate } \\
(\mathrm{ml} / \mathrm{s})\end{array}$ \\
\hline \multicolumn{5}{|c|}{ Conventional Pavement } \\
\hline 1 & 1000 & 500 & 478 & 1.05 \\
\hline 2 & 1000 & 500 & 425 & 1.18 \\
\hline 3 & 1000 & 500 & 433 & 1.15 \\
\hline Average & & & 445 & 1.13 \\
\hline \multicolumn{5}{|c|}{ Recycled Glass Pavement } \\
\hline 1 & 1000 & 500 & 223 & 2.24 \\
\hline 2 & 1000 & 500 & 242 & 2.07 \\
\hline 3 & 1000 & 500 & 251 & 1.99 \\
\hline Average & & & 239 & 2.10 \\
\hline \multicolumn{5}{|c|}{ Recycled Grit Pavement } \\
\hline 1 & 1000 & 500 & 673 & 0.74 \\
\hline 2 & 1000 & 500 & 705 & 0.71 \\
\hline 3 & 1000 & 500 & 719 & 0.70 \\
\hline Average & & & 699 & 0.72 \\
\hline
\end{tabular}



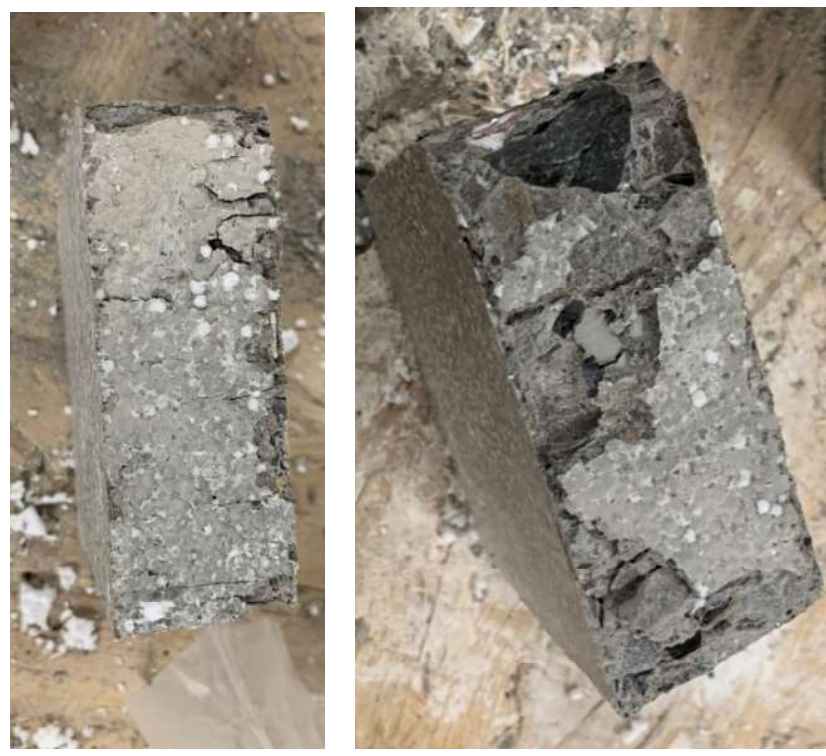

Fig. 22 Failure of concrete blocks when under compression

The expected compressive strength of concrete blocks cured for 28 days with a dimension of $(100 \mathrm{~mm}$ $\times 100 \mathrm{~mm} \times 100 \mathrm{~mm}$ ) is usually $40 \mathrm{Mpa}$. But because the blocks had a height of $50 \mathrm{~mm}$, the least value recorded was approximately $54 \mathrm{Mpa}$, as well as that the blocks were cured for 56 days, this might have impacted the values to be slightly higher than usual. When under compression, the blocks might fail and show some cracks on the surface of these blocks Fig. 22 shows the failure of concrete blocks when under compression.

\section{Infiltration Test Results}

A fixed volume of water was passed through each pavement type three times, and a duration for a fixed effluent volume was recorded. Results are shown in Table 8 and graphically illustrated in Fig. 23.

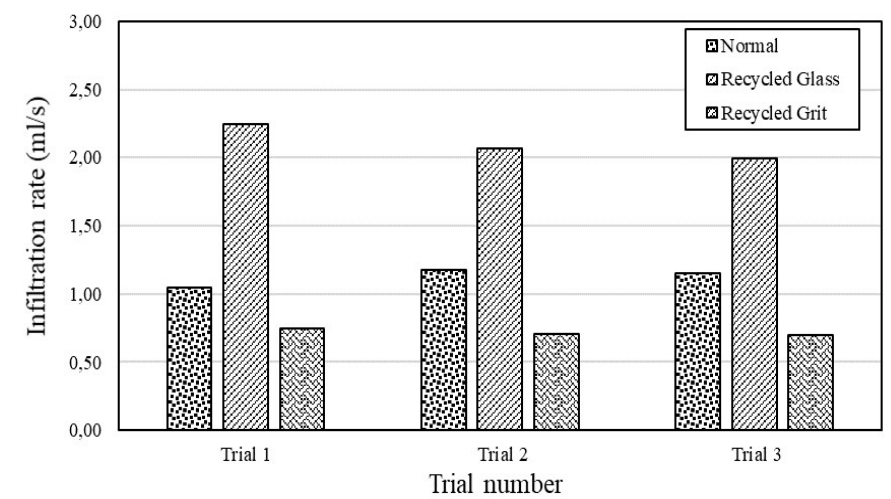

Fig. 23 Infiltration rate

As shown in Table 8 and Fig. 23, the pavement with recycled glass as a sub-base material exhibited the best performance when compared to both conventional and recycled grit pavements. This was due to the impermeable property of glass, which allowed water pass through the sub-base faster than other mixes. The pavement with recycled grit as a sub-base material took the longest time to drain the fixed amount of effluent (water). Hence, water samples from the PPS whilst carrying out laboratory testing for the hydrological performance occurred at the bottom of the wooden molds (Fig. 24). Furthermore, a high degree of percolation was evident as seen in Fig. 25, which was due to the super-saturation of the sub-base of the pavements can occur in extreme weather conditions, poor pavement maintenance, clogging issues and the sub-base soil seepage parameters.

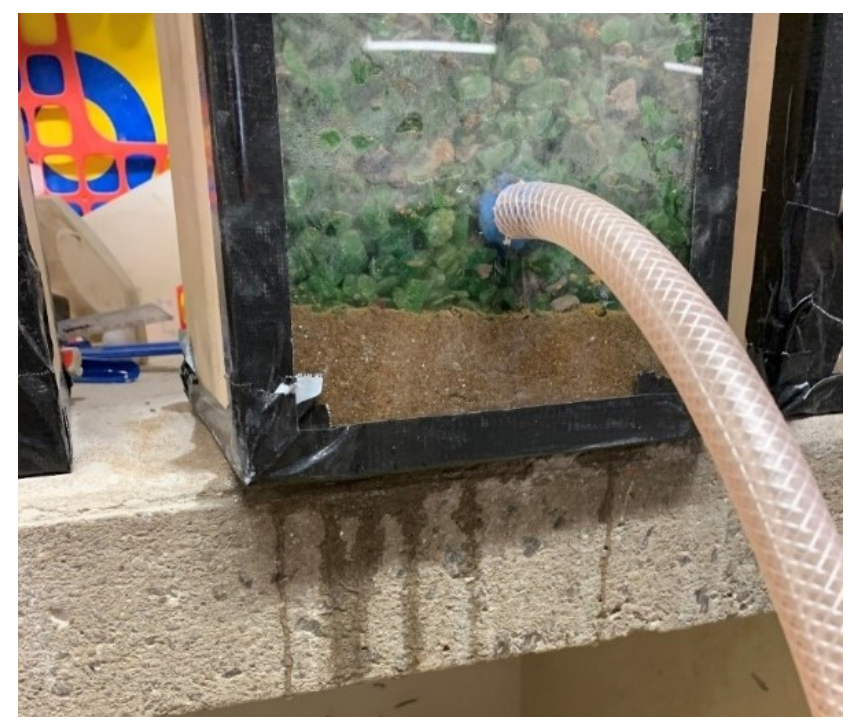

Fig. 24 Sample stormwater collection pipe for one of the permeable pavement systems (PPS)

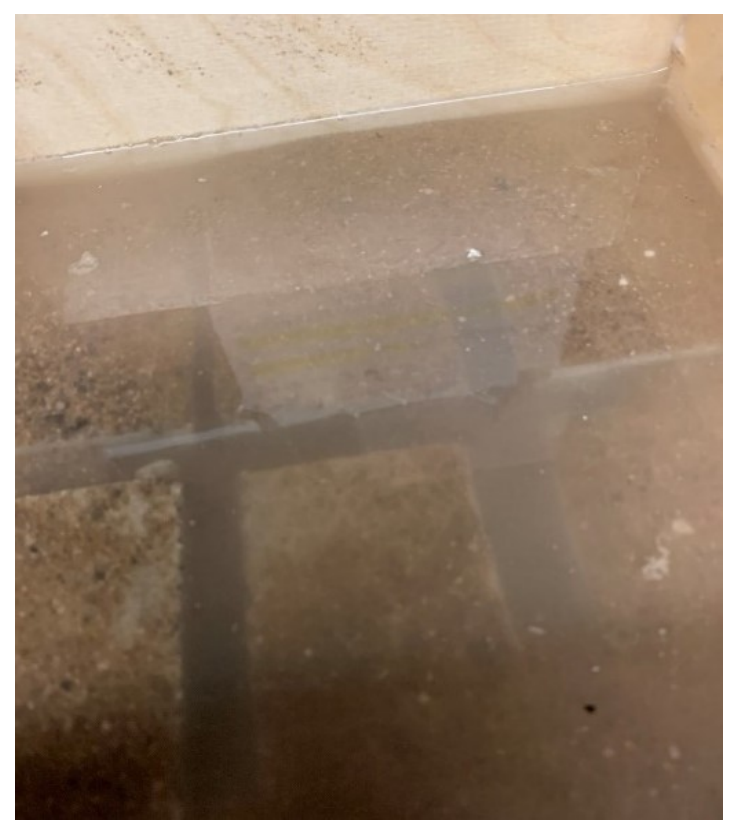

Fig. 25 Percolation and supersaturation of permeable pavement with recycled grit sub-base 


\section{Analysis of Results}

The various laboratory investigations in the current research have proved that low-carbon materials can perform as well as if not better in some situations than conventional materials. This is evident in the absorption test, where the mix with recycled grit exhibited superior performance, followed by the mix with recycled glass and rubber mix respectively. However, the mix with rubber material proved to be non-effective with a value equal to triple the amount of absorption for the recycled grit mix. This is dangerous as it can lead to problems associated with cold seasons such as the freezing of the stuck water in the blocks, which could lead to strength lose and disintegration of the developed pavement.

Additionally, when testing for the compressive strength of the permeable pavers, the mix with recycled grit provided the highest UCS value followed by the conventional and recycled glass, and 100\% recycled glass mix. This proves that recycled materials performed better in UCS than the conventional mix, while for the rubber blocks proved too light and brittle and it was not necessary to carry out compression tests on this type of mix, showing that not all recycled materials can perform better in concrete tests. Although the conventional mix did not perform as well as the recycled grit and glass mixes, it has proved that it can be used as a permeable paver. The compressive strength of the pavers is a crucial factor of determining their durability. For the infiltration test, the pavement with recycled glass as bedding aggregate $(2.5 \mathrm{~mm})$ and subbase $(10-20 \mathrm{~mm})$ proved to work the best when infiltrating water, this is due to the glass being impermeable, while the mix with fine recycled grit as bedding aggregate and sub-base took the longest duration to infiltrate the fixed amount of effluent water, this is due to the high absorption of water of the recycled grit mix, which also led to percolation on top of the surface of the pavement. Moreover, the block with the Conventional mix tool more time in infiltrating water than the pavement with recycled glass mix, the use of fine recycled aggregate to lower the carbon content of the pavement as the bedding aggregate in the Conventional mix pavement lead to this happening, as well as the sub-base might have absorbed a little amount of water. The pavement with the recycled grit mix has performed the best when tested for both absorption and compression, but when tested for infiltration, it came out to be the mix with most time to infiltrate the storm water which can lead to problems as shown in Fig. 26, however, the mix with recycled glass performed best when tested for infiltration, but when tested for absorption, the results came close to the performance of recycled grit, while when tested for compression, it showed lower values of strength.

Blocks made with rubber mix proved to be a nonefficient as it is so brittle such as shown in Fig. 26 and showed high values of water absorption which can lead to major problems such as thawing and water freezing in cold seasons. In addition, no permeable pavement was constructed form using the rubber as a way of reducing the carbon content of pavements due to the results of the tests applied.

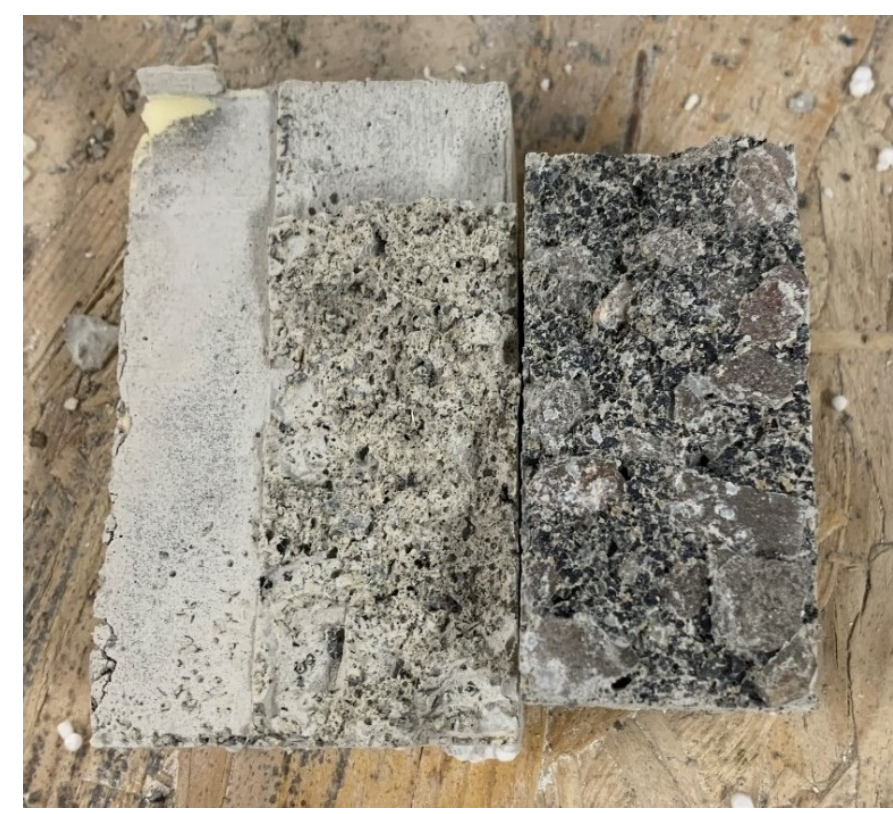

Fig. 26 Breaking of rubber blocks when striking

Table 9. Comparison of the performance of different concrete mixes

\begin{tabular}{|c|c|c|c|}
\hline Material & Absorption Test & Compression Test & Infiltration Test \\
\hline Conventional mix & 级 & $x$ & 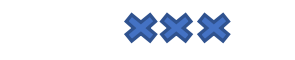 \\
\hline Recycled Glass mix & x经 & $x=2$ & 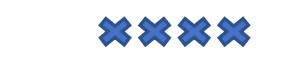 \\
\hline Recycled Grit mix & 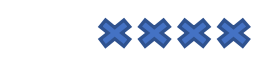 & 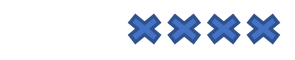 & 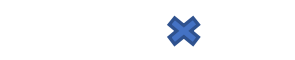 \\
\hline Recycled Rubber mix & $\approx$ & 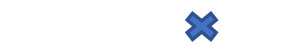 & No sample \\
\hline
\end{tabular}

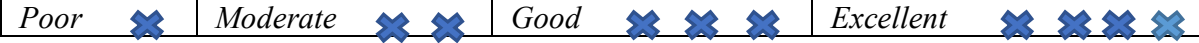




\section{Conclusion}

In conclusion, the present research investigated the use of low-carbon materials in the construction of permeable pavements. It was found that replacing recycled grit or recycled glass with sand when constructing permeable pavers has resulted in an increase of compressive strength, as well as both samples did a slightly better performance when tested for absorption. However, the recycled grit infiltrated the water much slower when used in the sub-bases of the pavements, this is due to the recycled mix being fine. While when using recycled rubber, the mix performed the worst within all mixes when tested for both absorption and compression. Therefore, Table 9 shows a summarized comparison between all four different mixes when tested:

Although the cost of using a permeable pavement section is ordinarily higher than cost of an ordinary pavement due to the regular inspection on the site which should be done on a regular basis, as well as the clearing and vacuuming of the permeable pavement surface, cost correlation of the whole permeable pavement framework contrasted with a regular pavement shows a sensible cost examination when considering the decrease or end of catch basins, underground piping, seepage ditches and stormwater management ponds required for conventional structures. In relation to the aim of the research which is whether recyclable materials can be used to substitute the use of conventional materials in the construction of permeable pavements when to reduce the high amounts of carbon emissions, the tests undertaken proved that when using suitable materials, low-carbon materials can perform as good as if not better than conventional materials such as shown in Table 9. To conclude the results, the use of recycled grit to replace sand in permeable concrete pavers with the use of recycled glass coarse aggregate as the subbase of a permeable pavement gives the most efficient yet sustainable combination to use. As a recommendation for future pavement infrastructure projects, the use of other low-carbon materials such as recycled plastic is essential. Plastic is a material that cannot decompose that easily, this has led to many problems such as the effect of plastic waste on living creatures in seas and oceans, so the inclusion of plastic in the construction of permeable pavements is essential get rid of extra waste. Moreover, the high availability of plastic waste makes the use of it cost-effective as well as that plastic is impermeable makes it a perfect material to use as a subbase to infiltrate water.

Finally, innovation on constructional materials is a crucial issue in this century, as well as that the world population is increasing rapidly, this research has led to an acknowledgment that low-carbon materials are efficient to use in permeable pavements and should be considered when constructing projects which have sustainability as a main goal. Further tests could also be performed to test the durability of the developed concrete pavement blocks. This test includes: Acid resistance test, Chloride attack test, Freezing and thawing resistance of pavement blocks, Sulphate attack test, Splitting tensile strength test, Drying shrinkage test, and Abrasion resistance test.

Acknowledgments The authors are grateful for the support of the International Water Security Network (IWSN) http://www.watersecuritynetwork.org/ provided. We thank our colleagues and technicians from the Civil and Environmental Engineering Cluster, University of the West of England, Bristol who provided insight and expertise that greatly assisted this research project.

\section{References}

ASTM C140-11a Standard Test Methods for Sampling and Testing Concrete Masonry Units and Related Units. West Conshohocken, PA, 2013: ASTM International.

ASTM C642 - 13. Standard Test Method for Density, Absorption, and Voids in Hardened Concrete. West Conshohocken, PA, 2013: ASTM International.

ASTM C936 / C936M - 13. Standard Specification for Solid Concrete Interlocking Paving Units. West Conshohocken, PA, 2013: ASTM International.

BS EN ISO 14040:2006. Environmental management - Life cycle assessment. Principles and framework. BSI Standards Ltd.

CD 226. Design for new pavement construction. Standards for Highway. Design Manual for Roads and Bridges (DMRB) Department for Transport.

Alsubih, M., Arthur, S., Wright, G. \& Allen, D. 2016. Experimental study on the hydrological performance of a permeable pavement. Urban Water Journal 14

Bayón, J. R., Castro, D., Moreno-Ventas, X., Coupe, S. J. \& NEWMAN, A. P. Pervious pavement research in Spain: Hydrocarbon degrading microorganisms. Proceedings of the 10th International Conference on Urban Drainage, 2005 Copenhagen/Denmark, 21-26 August 2005

Chopra, M., Kakuturu, S.-P., Ballock, C., Spence, J. \& WANIELISTA, M. 2010. Effect of rejuvenation methods on the infiltration rates of pervious concrete pavements. Journal of Hydrologic Engineering, 15, 426-433.

Evangelista, L. \& De Brito, J. 2010. Durability performance of concrete made with fine recycled concrete aggregates. Cement and Concrete Composites, 32, 9-14.

Greenblue-Urban. 2017. Permeable Pavement: The pros and cons you need to know [Online]. Available: https://www.greenblue.com/gb/permeable-pavement-the-prosand-cons-you-need-to-know/ [Accessed].

Guinée, J. B., Heijungs, R. \& Huppes, G. 2011. Life cycle assessment: Past, present, and future. . Enviromental Science and Technology. , 45, 90-96.

Hammes, G., Thives, L. P. \& Ghisi, E. 2018. Application of stormwater collected from porous asphalt pavements for nonpotable uses in buildings. Journal of Environmental Management, $222,338-347$. 
Hein, D. K., Swan, D. J. \& Schaus, L. 2010. Structural and hydrological design of permeable pavements. Transportation Association of Canada 2010 Annual Meeting. Montreal, Quebec.

Hoffmann, G. P. E., Stack, R. C. \& Van Wye, B. 2012. Stormwater management guidebook - Permeable Pavement Systems. In DISTRICT DEPARTMENT OF THE ENVIRONMENT, W. P D. (ed.). District of Columbia Center for Watershed Protection.

James, E. 2013. A Literature Review on the Effect of Porous Asphalt Roads on Water Pollution. In Sustainable Road Surfaces for Traffic Noise Control. In: EUROPEAN-COMMISSION (ed.). Ottawa, ON, Canada: Silvia Project Report.

Kayhanian, M., Anderson, D., Harvey, J. T., Jones, D. \& Muhunthan, B. 2012. Permeability measurement and scan imaging to assess clogging of pervious concrete pavements in parking lots. Journal of Environmental Management, 95, 114123.

Kia, A., Wong, H. S. \& Cheeseman, C. 2017. Clogging in permeable concrete: A review. Journal of Environmental Management, 193, 221-233.

Li, Y., Huang, Y., Quanliang, Y., Zhang, W., Meng, F. \& ZHANG, S. 2018. Multi-objective optimization integrated with life cycle assessment for rainwater harvesting systems Journal of Hydrology, 558, 659-666.

Maiolo, M., Carini, M., Capano, G. \& Piro, P. 2017. Synthetic sustainability index (SSI) based on life cycle assessment approach of low impact development in the Mediterranean area. Cogent Engineering, 4, 141-272.

Mata, L. A. \& Leming, M. L. 2012. Vertical distribution of sediments in pervious concrete pavement systems. ACI Materials Journal, 109, 149-155.

Minnesota-Stormwater-Manual. 2018. Types of permeable pavements [Online]. Available: https://stormwater.pca.state.mn.us/index.php/Types of permeabl e pavement [Accessed].

Montepara, A., Tebaldia, G., Marradi, A. \& Betti, G. 2012. Effect on Pavement Performance of a Subbase Layer Composed by Natural Aggregate and RAP. Procedia - Social and Behavioral Sciences, $53,980-989$

Palla, A., Gnecco, I., Carbone, M., Garofalo, G., Lanza, L. \& Piro, P. 2015. Influence of stratigraphy and slope on the drainage capacity of permeable pavements: Laboratory results. Urban Water Journal, 12, 394-403.
Paver-Search. 2020. How to Maintain Your Permeable Pavers? [Online]. Available: http://www.paversearch.com/permeablepavers-maintenance.htm [Accessed].

Pervious-Pavement. 2011. Structural Benefits [Online]. Available: https://www.perviouspavement.org/benefits/structural.html [Accessed].

Poon, C. S. \& Chan, D. 2006. Paving Blocks Made with Recycled Concrete Aggregate and Crushed Clay Brick. Construction and Building Materials, 20, 569 -577.

Poon, C. S., Kou, S. C. \& Lam, L. 2002. Use of Recycled in Molded Concrete Bricks and Blocks. Construction and Building Material 16, $281-289$.

Pratt, C. J. 1999. Use of permeable, reservoir pavement constructions for stormwater treatment and storage for re-use Water Science and Technology, 39, 145-151.

Pratt, C. J., Mantle, J. D. \& Schofield, P. A. 1995. UK research into the performance of permeable pavement, reservoir structures in controlling stormwater discharge quantity and quality. Water Science and Technology, 32, 63-69.

Priebe, M. 2009. Permeable Concrete Reduces Emissions [Online]. Available: https://blog.nwf.org/2009/12/permeable-concretereduces-emissions/ [Accessed].

Salah El-Deen, A., Bahnasawy, H. H., El-Hefnawy, A. A. \& Khafaga, M. A. 2004. Laboratorial and Applicable Study For the Use of Cement Dust in Egypt for the Production of Low Cost Building Material. 13 ${ }^{\text {th }}$ Arab-International Conference and Exhibition for Cement. Arabic Union for Cement and Building materials.

Terhell, S. L., Cai, K., Chiu, D. \& Murphy, J. 2015. Cost and Benefit Analysis of Permeable Pavements in Water Sustainability. University of California Agriculture and Natural Resources.

Tota-Maharaj, K., Grabowiecki, P., Babatunde, A. \& Coupe, S. J. 2012. The Performance and Effectiveness Of Geotextiles Within Permeable Pavements For Treating Concentrated Stormwater. Sixteenth International Water Technology Conference, IWTC 16 2012. Istanbul, Turkey.

Wang, T., Harvey, J. T. \& Jones, D. 2010. A Framework for LifeCycle Cost Analyses and Environmental Life-Cycle Assessments for Fully Permeable Pavements. In: California Department of Transportation, D. O. E. A., Storm Water Program (ed.). CA, USA: Institute of Transportation Studies.

Yong, C. F. \& McCarthy, D. T. A. 2013. Deletic Predicting physical clogging of porous and permeable pavements. Journal of Hydrology, 48-55. 